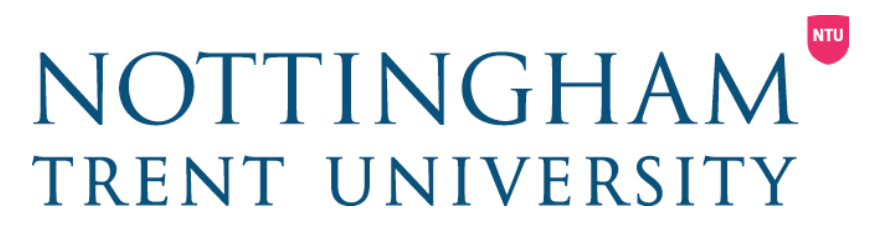

DISCUSSION PAPERS

I $\mathbf{N}$

ECONOMICS

No. 2008/ 16 ISSN 1478-9396

I NFLATI ON PERSI STENCE IN THE FRANC ZONE: EVI DENCE FROM DISAGGREGATED PRICES

Simeon COLEMAN

November 2008 


\section{DISCUSSI ON PAPERS IN ECONOMICS}

The economic research undertaken at Nottingham Trent University covers various fields of economics. But, a large part of it was grouped into two categories, Applied Economics and Policy and Political Economy.

This paper is part of the new series, Discussion Papers in Economics.

Earlier papers in all series can be found at:

http://www.ntu.ac.uk/research/school_research/nbs/overview/working_papers/index .html

Enquiries concerning this or any of our other Discussion Papers should be addressed to the Editor:

Dr Juan Carlos Cuestas

Division of Economics

Nottingham Trent University

Burton Street

Nottingham, NG1 4BU

UNITED KINGDOM

Email: juan.cuestas@ntu.ac.uk 


\title{
Inflation Persistence in the Franc Zone: Evidence from Disaggregated Prices
}

\author{
Simeon Coleman*
}

\begin{abstract}
In sub-Saharan Africa, where inflation persistence is likely to have deleterious welfare consequences, little attempt has been made to study this phenomenon. Using data over 1989:11-2002:09, this paper investigates persistence in disaggregated (food and non-food) inflation for thirteen Communauté Financière Africaine (CFA) member states using fractional integration (FI) methods. The results show that both inflation series are characterized by mean-reversion and finite variance, however it also exposes some asymmetry in inflation persistence across member states in both sectors. In Chad and Niger, the phenomenon is found to exist in both sectors. With uniform monetary policy across member states, implications for Monetary Policy, Nominal Convergence and Optimal Currency Area are then discussed.
\end{abstract}

Keywords: Fractional Integration, Inflation persistence, Franc zone.

* Department of Economics, University of Leicester, LE1 7RH, U.K. 


\section{Introduction}

Typically, maintaining price stability remains the mandate of monetary authorities and, a central bank's decisions and targets are influenced by how sluggishly inflation converges after a shock. Therefore, an understanding of the dynamic properties of inflation should be of more than academic interest, and of primary importance to policy makers. ${ }^{1}$ In particular, an improved knowledge about the dynamics of inflation provides policy makers with information on the short-term effects of monetary policy decisions. For researchers, this is crucial for forecasting the behavior of the economy following a shock or major monetary policy decision. Three additional points are worthy of note. First, accuracy of forecasts rest heavily on a forecaster's ability to adequately predict the pattern of absorption of the shock. Second, knowledge about the dynamics of inflation can provide valuable information regarding what motivates asymmetries in levels of inflation across countries or regions. For areas that are likely to be subject to common policy shocks, such as countries or regions within a monetary union, such knowledge is likely to be particularly interesting, informative and relevant. Third, the degree of persistence in inflation can have practical importance for the economy through its effects on wealth distribution and on economic efficiency. ${ }^{2}$ Moreover, the dynamic properties of inflation have important implications for the behavior of private agents. In recent years, much research has been conducted in this area of policy formulation; however, these studies have focused on more developed economies of Europe, the United States and the OECD countries. ${ }^{3}$ While such analysis is relevant for developed economies, they are likely to be even more (or at least, equally so) relevant for developing economies where centralgovernment sanctioned welfare system schemes are virtually non-existent or, at best, less developed. This is an area of research that has been virtually ignored for Africa, and one this paper seeks to address.

In relation to the welfare effects of shocks to inflation on the economy, and particular to developing African economies, Fielding (2004) simulates the response profiles of the aggregate consumer price index for three hypothetical income groups in response to a percentage point change in monetary policy instruments and examines how the effects of monetary policy decisions are likely to be shared between the rich and the poor in the West-African Economic and Monetary Union (UEMOA) of the CFA Franc zone. ${ }^{4}$ His results suggest that poorer households in a subset of countries within the UEMOA are more burdened by the price volatility that follows a change in monetary policy by the Central Bank than others. Given this background, and the practical implications

\footnotetext{
${ }^{1}$ Several papers including Angeloni et al. (2003), Coenen (2003) and Levin and Moessner (2005) make the explicit link between the design of monetary policy and the dynamics of inflation.

${ }^{2}$ In this paper, persistence in inflation relates to the time for inflation to return to the baseline after a shock.

${ }^{3}$ Working papers produced by the Eurosystem Inflation Persistence Network (IPN) of the European Central Bank (ECB) fall into this category.

${ }^{4}$ The study examined disaggregated price inflation data (i.e. food and non-food price inflation for the major urban cities for each country) and considers the stock of currency in circulation in the UEMOA (m) and the central bank's base interest rate (r) as the two monetary policy instruments. The author's sample included Cotonou (Benin), Ouagadougou (Burkina Faso), Abidjan (Côte d'Ivoire), Bamako (Mali), Niamey (Niger), Dakar (Senegal), and Lomé (Togo).
} 
for wealth distribution and economic efficiency, sluggishness of inflation in returning to a target after a change in central bank's monetary policy may have deleterious implications for welfare, especially of the poor. ${ }^{5}$ Findings from this area of research should, therefore, be of considerable policy importance vis-à-vis welfare of the poor. Of direct interest, to both policy makers and researchers, will be sector-specific inflation (e.g. food) persistence within a monetary area. Two interesting policy issues emerge: First, major asymmetries in the levels of persistence in inflation across countries (or regions) within a monetary area is likely to make policy formulation particularly difficult, as it will result in some clear net gainers and losers. For the net losers, the incentive to renege on commitment to the union is likely to be higher, thereby threatening the stability of the monetary union. Second, differing degrees of persistence across sectors will suggest asymmetry in effects of monetary policy within each member state, and may hurt a section of the public.

A primary aim of this paper is to uncover underlying asymmetries in inflation dynamics, and policy implications, across countries that are typically considered to have similar dynamic properties. This is achieved by identifying member states that show inflation persistence and those that do not. It examines data disaggregated to food and non-food level across thirteen Communauté Financière Africaine (CFA) countries i.e., CFA Franc zone, which is particularly interesting in the light of the following. First, the Franc zone represents the oldest multinational single currency monetary arrangement currently in existence. Second, despite the fact that inflation rates in the Franc zone have been typically shown to be both low and stable relative to other sub-Saharan African countries, some recent studies (for example Fielding, 2004) have shown that some significant asymmetries may actually exist among member states regarding the short-term response of prices to a shock in instruments of monetary policy. Third, each of the two groups of countries that make up the two monetary unions of the Zone is subject to monetary policy formulated by their regional central bank, and hence countries within each of these unions are likely to be subject to similar monetary policy shocks. Fourth, such research is urgently needed given the stated intentions of many African countries themselves, including the Organization for African Unity and the Association of African Central Bank Governors promoting formation of regional monetary unions. Focusing on Africa, such proposed unions include the West-African Monetary Zone (WAMZ) comprising the English-speaking members of the Economic Community of West African States (ECOWAS); and the South African Development Community (SADC) monetary union comprising the Southern African countries - both of which are yet to fully take off, however, these countries can learn a lot from the Franc zone. The availability of disaggregated data for each country in our sample allows for analysis of both country-specific and sector-specific inflation persistence for the Franc zone.

Traditionally, tests of inflation dynamics provide a knife-edge analysis, by classifying inflation as either having a unit-root or not (i.e., $\mathrm{I}(1)$ or $\mathrm{I}(0)$ ) having used standard unit-root tests such as the ADF and KPSS tests. However, analysis of the dynamics of

\footnotetext{
${ }^{5}$ Some earlier work by Romer and Romer (1998) and Easterly and Fisher (2000) provides empirical evidence establishing the relationship between monetary policy and well-being of the poor. Both studies support the view that, on average, low inflation is welfare-improving. In the light of these studies, the short to medium-term effects of monetary policy decisions may therefore prove very important for welfare, particularly of the poor.
} 
time-series focussing on the memory (persistence) in the series using other less restrictive methods has increased in popularity. Although there is not, as yet, a consensus on how to model the inflation rate, recent studies provide robust evidence supporting a Fractional Integration (FI) processes. ${ }^{6}$ In this paper, we assess the dynamics of inflation by determining the order of integration based on the FI process. Specifically, we analyze the existence of persistence (or memory) for food and non-food price inflation rates in thirteen Franc zone countries using three hugely popular semi-parametric methods proposed by Geweke and Porter-Hudak (1983), Phillips (1999a,b) and Robinson (1995) respectively. We then discuss some policy implications of inflation persistence for these economies. ${ }^{7}$ The results support the widely believed view of a fairly stable inflation across the Franc zone; however, some asymmetry is evident among member states regarding the extent of persistence in sector-specific inflation. This may have implications for people spending a larger proportion of their income on a sector that experiences persistence after a shock. ${ }^{8}$

While determining the causes of any observed inflation persistence would be important, it falls outside the scope of this paper. However, for completeness, we make mention of some studies that attempt to address this issue. Amato and Laubach (2003) provide a theoretical analysis of this issue, and review some studies that focus on this area of research. Factors suggested as potential reasons in their review include (i) the sluggish response of firms' real marginal cost to fluctuations in output (Sbordone, 2002; Galí and Gertler, 1999), and (ii) allowing the choice of some agents (price-setters) to deviate from optimal behavior due to limited capability of forming fully rational expectations (Roberts, 1997). The assumption of a possible 'rule-of-thumb' behavior by a fraction of firms in price-setting is then further explored by the authors. ${ }^{9}$ Backward-looking indexation and uncertainty about the degree of indexation, uncertainty about the fraction of 'rule-of-thumb' price-setters, and uncertainty about the degree of price and wage indexation are also suggested reasons for inflation persistence (see Levin and Moessner (2005)). In this study, the point of interest is the existence and possible consequences of inflation persistence, and not the causes.

The rest of the paper is structured as follows. Section 2 presents a brief review of the macroeconomies of the countries under consideration. Section 3 describes the empirical methodologies applied in this paper. Section 4 presents the data sources and empirical estimates, and Section 5 discusses some policy implications of our results. Section 6 summarizes and concludes.

\footnotetext{
${ }^{6}$ See examples, Gadea and Moyoral (2006) and earlier work by Baillie (1996) and references cited therein.

${ }^{7}$ To the author's knowledge, this is the first study which investigates asymmetries in sector specific inflation persistence for the CFA Franc zone; and as described above, the findings should significantly inform policy decisions.

${ }^{8}$ Intuitively, the poor will spend a larger proportion of their income on food. Hence, persistence in the food sector is likely to make the poor relatively worse off.

${ }^{9}$ The 'rule-of-thumb' that the authors consider implies that decisions by a fraction of the population today mimic yesterday's behavior of all agents (including the optimizing agents).
} 


\section{Macroeconomic State}

The CFA Franc zone, as it stands today, has been the subject of much empirical research and discussion. The subject of such research particularly relates to how this group of countries are working together, being tied together largely as a result of what has been described as a 'historical accident' of being colonized by France rather than, say, Britain. Given that the grouping of the different countries into the two monetary unions that make up the CFA Franc zone (UEMOA and CEMAC) was largely aimed at easing the burden of administration, rather than on any sound economic rationale, it is possible (even likely) that countries with significant macroeconomic differences have found themselves in a common monetary union. The essential role of the single central bank is one of the fundamental features of any monetary union, hence large and persistent macroeconomic differences among member states are likely to make policy formulation and coordination among member states extremely difficult.

"Tables 1 - 3 here"

The potential for unequal welfare costs in some member states makes the issue of heterogeneity particularly relevant to zone-wide policy formulation. Similarities (or differences) will have important implications for the conduct of monetary policy by the central bank, and how their policies address the needs of individual member countries. For this reason also, this paper considers the view that it is of more practical relevance for such studies to focus on country-level analysis, rather than (the more contentious) aggregated analysis. It may also be the case that the current grouping is indeed optimal, with each zone's member states showing significant macroeconomic similarities, which would then be an extremely happy accident. On the one hand, it is likely that countries with similar production structures may show similar responses to macroeconomic shocks. On the other hand, data reported in Tables 1 - 3 show that some marked differences exist in national income and development criteria, indicating that an a priori assumption of similar responses to (or relevance of) shocks may be misleading.

\section{Empirical Methodology}

In order to check robustness of our results, and confirm the presence (or absence) of persistence in the series, we obtain our estimates of the fractional differencing parameter, $d$, using three separate semi-parametric methods, and different sample sizes. ${ }^{10}$

\subsection{Fractional Integration Estimation Methods}

Generally, the model of an autoregressive fractionally integrated moving average process of order $(p, d, q)$ is denoted by $\operatorname{ARFIMA}(p, d, q)$. For a series $y_{t}$ with mean $\mu$, such a process may be written using operator notation as:

$$
\Phi(L)(1-L)^{d}\left(y_{t}-\mu\right)=\Theta(L) \epsilon_{t}
$$

\footnotetext{
${ }^{10}$ Here, sample size refers to the number of harmonic ordinates in the spectral regression.
} 
where $\epsilon$ iid $\left(0, \sigma_{\epsilon}^{2}\right), L$ is the backward-shift operator, $\Phi(L)=1-\Phi_{1}(L)-\cdots-\Phi_{p} L^{p}$; $\Theta(L)=1+\varphi_{1} L++\varphi_{q} L^{q}$, and $(1-L)^{d}$, the fractional differencing operator, may be defined as a hypergeometric function:

$$
(1-L)^{d}=\Sigma_{k=0}^{\infty} \frac{\Gamma(k-d) L^{k}}{\Gamma(-d) \Gamma(k+1)}
$$

where $\Gamma($.$) represents the gamma function and the fractional differencing parameter, d$, is allowed to assume any real value and determines the order of integration of the series. ${ }^{11}$ In fact, for any

$$
\left.(1-L)^{d}=1-d L+\frac{d(d-1)}{2 !} L^{2}-\frac{d(d-1)(d-2)}{3 !}\right) L^{3}+\ldots
$$

The infinite-order autoregressive representation of fractional white-noise is given by:

$$
y_{t}=\sum_{k=0}^{\infty} \pi_{k} y_{t-k}+\epsilon_{t}
$$

In principle, the $d$ parameter is used to determine the extent of persistence in the series. If $d=0$ in Equation 1 then $y_{t}$ corresponds to a stationary and invertible ARMA process and can be said to exhibit short-memory [i.e. $\mathrm{I}(0)$ ]. Alternatively, when $|d|=1$, it corresponds to the unit root case and the series is nonstationary and non-mean-reverting [i.e. $\mathrm{I}(1)$ ]. However, there is the possibility that the order of integration is neither $\mathrm{I}(0)$ or $\mathrm{I}(1)$, and $\mathrm{d}$ is fractional (i.e. $0<|d|<1$ ). Generally, if $d>0$ in Equation 1, $y_{t}$ is said to be a long-memory process, so-called because of the strong degree of correlation between observations widely separated in time. However, if $|d|<0.5$, and all roots of $\Phi(L)$ and $\Theta(L)$ lie outside the unit-circle then $y_{t}$ is covariance stationary and meanreverting. Alternatively, if $|d| \in(0.5,1)$ then $y_{t}$ is no longer covariance stationary, but is still mean-reverting with the effects of the shocks dying away in the long run. Table 4 summarizes the properties of the different values of $d$ in relation to the variance, shock duration and stationarity for $y_{t}$.

\section{"Table 4 here"}

Interestingly, when $|d| \in(0,0.5)$, some distinctions can be made as follows. On the one hand, when $d \in(0,0.5)$ and $d \neq 0$, Hosking (1981) showed that the correlation function, $\rho()$, of an ARFIMA process is proportional to $k^{2 d-1}$ as $k \rightarrow \infty$. In other words, the autocorrelations of the ARFIMA process decays hyperbolically to 0 as $k \rightarrow \infty$, slower than the faster, geometric decay of a stationary ARMA process; such an ARFIMA process is said to exhibit long-memory. On the other hand, for $d \in(-0.5,0)$, and $d \neq 0$ the process is said to exhibit long-range negative dependence (or anti-dependence), and is still mean-reverting. ${ }^{12}$ A significantly negative estimate of $d$ (inside this range) for our inflation series would therefore imply mean reverting behavior for the given price series.

\footnotetext{
${ }^{11}$ We note that in practice since $(1-L)^{d}$ is an infinite lag order, a truncation method needs to be applied in each method method to estimate the $d$ parameter. Also, the standard autoregressive integrated moving average (ARIMA) model is obtained by the arbitrary restriction of $d$ to integer values.

${ }^{12}$ Baum et al. (1999b) refer to this process as Intermediate Memory.
} 
It is worth mentioning that these methods were pioneered by Granger and Joyeux (1980), Granger (1980), and Hosking (1981). More recently, some theoretical justification has been provided by Parke (1999) in terms of duration of shocks (using an ErrorDuration model). Considering the cumulation of a sequence of shocks that switch to zero after a random delay, Parke shows that if the probability that a shock survives for a $\mathrm{k}$ periods (say $p_{k}$ ) decreases with $k$ at the rate $p_{k}=k^{2(d-1)}$ for $\mathrm{d} \in(0,1]$ then the errorduration model generates the same autocovariance structure as an $\mathrm{I}(d)$ process. Baillie and Bollerslev (1994), and Gil-Alaña and Robinson (1997) and Baum et al. (1999a,b) also provide some relevant empirical applications of fractional models. ${ }^{13}$ Upon re-examining an earlier study on cointegration relationships between seven nominal exchange rates, Baillie and Bollerslev (1994) rather find evidence of long memory, and hence fractionally integrated process. Re-accessing an extended version of the Nelson and Plosser (1982) data set, Gil-Alaña and Robinson (1997) also show that although traditional unit-root tests by Nelson and Plosser failed to reject the null of a unit-root, when the possibility of fractional integration is allowed the results are less clear cut. In fact, when the residuals $\left(e_{t}\right)$ are considered to be white-noise, they find evidence for the rejection of the unit root hypothesis in as many as five series, but less when $e_{t}$ is AR. Baum et al. (1999a,b) allow for the possibility of fractional dynamic behavior in investigating whether absolute purchasing power parity (PPP) did hold as a long-run equilibrium concept during the post-Bretton Woods period of flexible exchange rates (1999a) and in international inflation rates (1999b) respectively. In the first case, their findings, even allowing for fractional dynamic behavior, does not support absolute long-run PPP in all cases considered. In the second, regarding world inflation rates, the authors find substantial evidence to support fractional dynamic behavior.

A number of methods can easily be found in the existing literature to adequately estimate, and test the statistical significance of, the fractional differencing parameter, $d$, and can broadly be categorized as either parametric or semi-parametric. With the parametric methods [see examples in Fox and Taqqu, (1986); Dahlhaus (1989); Sowell (1992); Robinson (1994)], the model is specified up to a finite number of parameters. However, with such an approach, the correct choice of the model is important and if it is misspecified, the estimates may be inconsistent. In other words, misspecification of the short-run components of the series tends to affect also the long-run parameter estimates. Due to these disadvantages, some studies on the topic advocate semi-parametric methods which do not require an exact model specification [see examples in Phillips (1999a,b), Robinson (1995), Baum et al. (1999a,b)].

In this paper, we have used three semi-parametric methods - the spectral regression [Geweke and Porter-Hudak (1983)], the modified spectral regression [Phillips (1999a,b)], and the Gaussian semi-parametric approach [Robinson (1995)] - to estimate the fractional differencing parameter $(d)$ and assess the robustness of the estimates. ${ }^{14}$

Prior to any further analysis, we note that some recent empirical studies, including Batini (2002) and Levin and Piger (2004), have shown that the presence of structural breaks

\footnotetext{
${ }^{13}$ An extremely thorough summary and an extensive review of estimation methods is provided by Baillie (1996), and references cited therein.

${ }^{14} \mathrm{~A}$ brief description of the three methods is provided in Appendix A.
} 
in a series may lead to some misleadingly high parameter estimates of the persistence measure. To avoid the potential problem of spurious overestimation of the persistence parameter $(d)$ by not accounting for the occurrence of a structural break(s), we first test for the presence of any such breaks in the mean of each series by applying the procedure of Bai and Perron (2003) [hereafter BP], and allowing for the possibility of up to 5 breaks. ${ }^{15}$

\section{Data and Empirical Estimates}

\subsection{Data}

The dataset comprises monthly food and non-food price inflation series for thirteen individual member states within the CFA Franc zone of sub-Saharan Africa: Benin (Ben), Burkina-Faso (Bfaso), Côte d'Ivoire (Civ), Mali (Mal), Niger (Nig), Senegal (Sen) and Togo (Tog) and Cameroon (Cam), Central African Republic (CAR), Chad (Chd), Congo Republic (Con), Equatorial Guinea (Geq) and Gabon (Gab). This dataset was extracted from the BCEAO publication, Indices Harmonisés des Prix à la Consommation des Etats de l'Union Economique et Monétaire Ouest Africaine. Guinea-Bissau is not included in this study due to insufficient data for that country. Generally, the dataset spans the period 1989:11-2002:09, although the period is significantly less for some countries - see Figure 1 for an illustration of the series. Prior to any analysis, it is worth noting here that the data relates specifically to urban price inflation and does not cover rural areas in the member states, and the results and any analysis will therefore be applicable to urban areas.

\subsubsection{Structural Break Tests}

We apply the procedure proposed by BP allowing for up to $k=5$ breaks in each series, and in accordance with the sample sizes we suppose a trimming parameter $t=0.15$. The minimal segment length $(h)$ is defined by BP as the integer value of the product of the trimming parameter $(\mathrm{t})$ and the number of observations of the dependent variable $(\mathrm{T})$ i.e., $h=\operatorname{int}(t(T))$ in a GAUSS algorithm. Primarily, the method tests for changes in the levels of the series by considering the representation $\pi_{t}^{i}=\varphi+\varsigma_{t}^{i}$, where $\varphi$ is a constant capturing the level of the series and $\varsigma_{t}^{i}$ is a (short-memory) linear process. The main focus of attention here are any sharp changes of the level, $\varphi$. A nonparametric correction is embedded in the algorithm to take account of autocorrelation and heteroscedasticity in the process $\varsigma_{t}^{i}$. Table 5 summarizes the number of breaks suggested by the three main structural break tests (and confirmatory tests in Tables 6 and 7 ) within the procedure. ${ }^{16}$

"Tables 5 - 7 here"

\footnotetext{
${ }^{15}$ In Bai, J. and P. Perron (2003), the authors have made available a GAUSS procedure to apply a range of methods that can be used to determine multiple structural breaks in the mean of a series.

${ }^{16}$ For the interested reader, some further detail on these structural break tests has been provided in Appendix $\mathrm{C}$ of this paper.
} 
Based on the results from all the confirmatory break tests reported in Tables 6 and 7 , the test statistics do not reject the absence of any significant breaks at the $5 \%$ level of significance. BP advice that due to the downward bias that is sometimes observed with the information criteria, the SP test is usually preferred (p. 17). Secondly, the authors submit that:

When no serial correlation is present in the errors, but the lagged dependent variable is present, the BIC performs badly when the coefficient on the lagged dependent variable is large. In such cases the modified SIC (LWZ) performs better...The method suggested by $\mathrm{BP}$ is based on the sequential application of the supF test..." (p. 15).

As this applies in our case, we therefore conclude in favor of zero breaks in the mean. Based on these results, the possibility of spurious overestimation is reduced.

\subsection{Fractional Integration Estimates}

The restrictiveness of standard unit-root tests, particularly regarding low-frequency dynamic behavior, may underlie the failure to reject the unit-root hypothesis in inflation as has been observed in some studies, as has been described in Baum et al. (1999a) for a review of some previous studies and some discussion of conflicting evidence found in some earlier studies. By allowing the order of integration of a series to take any real value, fractional integration estimates avoid the possibility of only the knife-edge $I(0) / I(1)$ situation. Therefore, by means of the $d$ parameter, a wider range of mean-reverting dynamics can be found.

An important feature of periodogram-based methods, such as the semi-parametric methods employed in this paper, is that they require the choice of the number of lowfrequency periodograms to be used in the estimation. In fact, the estimate of $d$ is likely to be biased if an improper inclusion of medium- or high- frequency periodograms is used; alternatively, too low-frequency periodograms is likely to increase sampling variability of the estimates. As a sensitivity and robustness check, our results in Tables $8-13$ each report estimates of $d$ (including standard-errors) for various estimation sample sizes $(v=)$ 20, 30, 40, 50 and 60. For each table of results, as expected, the lower periodogram ordinates (e.g. $v=20,30$ and 40) typically display higher standard-errors than when $v$ is higher.

Due to the number of observations in each series [lowest: 83 and highest: 152], high sampling variability, typical in lower periodograms, is likely to bias the estimates. Therefore, the discussion of the evidence is typically based on estimates obtained for higher ordinates, $v=50$ and 60 . Evidence for non-food price inflation is presented first, followed by that for the food price inflation. ${ }^{17}$

\subsubsection{Empirical Estimates for Non-food Price Inflation}

The estimates of the fractional integration parameter $(d)$, as obtained from the three estimation methods, for the non-food price inflation rates are reported in Tables 8 - 10

\footnotetext{
17 All estimates are obtained using STATA 8.
} 
for each individual country in our sample.

"Tables 8 - 10 here"

Table 8 reports estimations based on the spectral regression approach [Geweke and Porter-Hudak (1983)] and reveal somewhat mixed evidence across member states. Generally, the estimates are fairly stable across estimation sample size $(v)$, but less so in the case of Central African Republic. The $d$ estimates for the non-food price inflation are typically not significantly different from zero, except in five countries - Cameroon, Chad, Gabon, Niger and Senegal - which are statistically significant and positive. Thus, there is some evidence of long-memory in non-food price inflation for these five member states, although they remain below 0.5 (i.e. $|d| \in(0,0.5)$ ). There is also some evidence of long-memory for the largest economy of the Franc zone, Côte d'Ivoire when $v=60$, however this is only statistically significant at the $10 \%$ level.

Table 9 reports the estimates of $d$ based on the modified spectral regression approach [Phillips (1999a,b)]. The results are generally similar to that reported in Table 8, and the estimates of $d$ for non-food price inflation in the same five countries - Cameroon, Chad, Gabon, Niger and Senegal - are statistically significant and positive, but remain below 0.5. With the possible exception of Central African Republic, the estimates are broadly stable across $v$ for all member states.

Table 10 also reports estimates of $d$ based on the method proposed by Robinson (1995). Regarding evidence for the presence of long-memory in non-food price inflation, similar conclusions can be drawn as from the above methods. This is true with the exception of Cameroon, for which Robinson's approach cannot be applied for $v>20$, due to construction and estimation sample size. In fact, to avoid biasing the estimates, Robinson(1995) suggests that $v=0.5 T$. Therefore, evidence for the presence of longmemory in non-food price inflation is confirmed for Chad, Gabon, Niger and Senegal, but not for Cameroon, due to the small overall sample size of 83 .

The results reported in Tables 8 - 10 broadly reinforce the presence of long-memory for non-food price inflation in Cameroon, Chad, Gabon, Niger and Senegal, but not in the other member states. Based on Tables 1 - 3, these consist what may be described as both 'weaker' and 'pivotal' member states.

\subsubsection{Empirical Estimates for Food Price Inflation}

Estimates of the fractional integration parameter $(d)$ for food price inflation rates for each individual country in our sample, as reported in Tables 11 - 13, are obtained by applying similar methods. The discussion in this section is presented for each table in sequence.

"Tables 11 - 13 here"

Estimates of $d$, based on the Spectral Regression method, and reported in Table 11, indicate the absence of long-memory for food price inflation in most member states. However, in Chad, Equatorial Guinea, and Niger the estimates of d are significantly different from zero, particularly for higher estimation sample sizes $(v=50$ and 60). 
There is also some evidence of long-memory for Togo when $v=60$, however this is only statistically significant at the $10 \%$ level; also for Central African Republic, some evidence of long-memory exists only for small sample sizes $(v=20,30$ and 40), but not for higher estimation sample sizes. Interestingly, estimates of $d$ for Equatorial Guinea are found to be negative and statistically significant, suggesting intermediate-memory (anti-persistence). ${ }^{18}$

The Modified Spectral Regression estimates of the fractional differencing parameter for food price inflation series are reported in Table 12. The evidence of long-memory detected here is broadly consistent with the corresponding spectral regression estimates for food price inflation and confirm statistical significance of $d$ in Chad, Equatorial Guinea and Niger. Again, for Central African Republic, evidence of long-memory exists only when $v=20,30$ and 40 are considered, which may be due to the inherent variability brought about by the small estimation sample size.

The Gaussian Semi-parametric Regression estimates of the fractional differencing parameter for food price inflation series are reported in Table 13. The estimates reported in the table provide support for the evidence of long-memory found earlier for Chad, Equatorial Guinea and Niger. Similarly, the estimates of d for Equatorial Guinea are negative and statistically significant $(-0.5<d<0)$. Again, the estimates of $d$ obtained for Central African Republic are only statistically significant (and positive) for smaller sample sizes $(v=20,30$ and 40$)$, but not for higher estimation sample sizes. For Togo, the estimate is only statistically significant at the $10 \%$ level when $v=60$.

The results reported in Tables 11 - 13 reinforce the evidence of the presence of some persistence in food price inflation for Chad, Equatorial Guinea and Niger. An obvious inconsistency between the estimates obtained for food price inflation is the strong evidence of long-memory for food price inflation in Benin and Togo found from the modified spectral regression estimates, but not in the spectral regression and the Gaussian semiparametric regression approaches. With two of the three estimation methods suggesting no statistically significant estimates of $d$ in Benin and Togo, the results are not as robust and conclusive. In this case, based on Tables $2-3$, it is mainly the member states lowest in the scale of what we can describe as 'weaker' member states (that is Niger and Chad) that have the problem of inflation persistence in the food sector. Classifying Equatorial Guinea is not straightforward, given that although it has a high GDP per capita and rates fairly high on the HDI scale (See Table 1) these increases in the national income are fairly recent and is due to the oil revenues, as can be inferred from the past GDP values as reported in Table 2.

Figure 2 presents six representative impulse response graphs based on the spectral regression [Geweke and Porter-Hudak (1983)] estimates. In the case of Equatorial Guinea (Geq) where the fractional integration parameter for the food sector is such that $-0.5<$ $d<0$ and statistically significant, the impulse response graphs show that the impulse decays somewhat faster than the non-food sector, where $d$ is not statistically significant, confirming the anti-persistence feature. In the case of Gabon (Gab) and Cameroon (Cam), both represent the case where $d$ for the non-food sector is positive and statistically

\footnotetext{
${ }^{18}$ See impulse response function graphs for Equatorial Guinea (FGEQ and RGEQ) in Figure 2 for an illustration of anti-persistence.
} 
significant $(0<d=0.5)$, while not significantly different from zero for the food sector. Finally, for the case of Chad and Niger, where our results indicate positive $(0<d<0.5)$ and statistically significant estimates of $d$ for both sectors, the unit-shock persists much longer prior to settling, compared to the case of no persistence.

\section{$5 \quad$ Policy Implications}

The degree of persistence in inflation has potentially important implications for theoretical models in monetary economics and macroeconomics. For the monetary union, three potential areas for which the observed asymmetries may have important implications include (i) the conduct of monetary policy; (ii) differences in the fundamental macroeconomic structure across member states; and (iii) the Optimum Currency Area (OCA) theory.

\subsection{Monetary Policy}

In principle, the primary goal of policy makers in a monetary union, regarding monetary policy, is to maintain price stability in member states while maintaining a healthy level of foreign reserves. Intuitively, inflation persistence is likely to have immediate consequences for the conduct of monetary policy, particularly due to the inflation differentials. The consequences for policy design has received some attention in recent times in empirical literature. Benigno and Lopez-Salido (2002) find that heterogeneity in inflation persistence among different regions of the Euro area may imply sub-optimality of certain policies, such as the targeting of Euro-wide HICP. They suggest a weighting system for policy design, where a greater weight is assigned to regions with higher persistence. Within the Franc zone, available policy instruments for the conduct of monetary policy include base interest rates, reserve assets ratio and credit ceilings on government borrowing and private sector lending; and policy decisions by the central banks (BCEAO and BEAC) are applicable to the group of countries within its jurisdiction. Since the 1994 collective devaluation of the CFA Franc (CFAF), some significant reforms have been implemented and both central banks appear to have reorganized and are more open, even issuing regular communiqués to better inform the public. It is expected that changes in monetary policy, particularly when it has a direct impact on available money growth, will influence prices and hence inflation. Therefore, if the central bank policy makers implement a change in monetary policy, and influence inflation in individual member states, the asymmetries observed suggest that being in a monetary union does not necessarily guarantee similar effects of the policy across all member states. Specifically, any disturbances in inflation in the non-food sector of Cameroon, Chad, Gabon, Niger and Senegal; and the food sectors of Central African Republic, Togo, Equatorial Guinea and two 'weakest' economies of Chad and Niger, are likely to persist, thereby placing more of a burden on those who spend a larger proportion of their income on the given sector. A possible resolution may be for these countries to put in place dedicated programmes of action in anticipation of the social (welfare) costs of changes in policy that affect inflation e.g., by issuing food stamps to certain income groups, and possibly providing targeted 
subsidies for domestic producers. This may be along the lines of the Programme of Action to Mitigate the Social Consequences of Adjustment (PAMSCAD) the Government of Ghana introduced in 1987, on realizing the social costs that the structural adjustment programme was inflicting on the general populace. Although the success of that programme is a matter of debate, the recognition of the problem was a step in the right direction. Second, the central banks may need to provide funds to support such countries after a policy change, in an attempt to ensure smooth running of Zone. Although these net-losers do not altogether need to abandon monetary policy from the central bank, an awareness of the possible persistence is crucial. In fact, higher persistence (transmission lag) is likely to render monetary policy measures ineffective due to the possibility of interim additional shocks to inflation and further complicating appropriate monetary policy formulation. The credibility of the central bank's monetary policy should be of significance in offsetting the concerns of wage setters to stabilize expectations and ease inflation persistence.

\section{$5.2 \quad$ Nominal Convergence}

Another interesting aspect of the monetary union relates to differences in the prevailing macroeconomy of member states (see Tables 1 - 3). Differences in inflation levels, wage structures, levels of foreign debt to GDP, average tax revenues, capital spending and per capita income may further compound the observed asymmetries by influencing the ability of these countries to respond promptly and adequately to a shock. For example, annual per capita GDP in the Congo, Mali and Niger is less than $\$ \mathrm{US1}, 000$, whiles countries such as Cameroon, Equatorial Guinea, Gabon have per capita income above $\$$ US2,000. ${ }^{19}$ In effect, when responding to an inflationary shock, the ability to implement alleviation measures is likely to be influenced by these economic realities. For example, although issuing food stamps and/or the release of targeted subsidies for food production may lesson the adverse effects of inflation persistence, access to funds may prove problematic. Under an assumption of policy makers' willingness to promptly address such a problem, a potential pitfall would be the country's monetary inability to adequately provide such assistance.

With nominal interest rates similar within each monetary area (UEMOA and CEMAC), asymmetry in inflation persistence also suggests asymmetry in real interest rates across member states. In such situations, higher inflation countries will have lower real interest rates which will tend to stimulate investment and consumption, and lower the real interest expense on public debt. In the Franc zone there is some evidence of inflation dispersion across member states (see Figures 3 - 6), however, prices have generally tended to move together, albeit not exactly. In the presence of asymmetry in inflation persistence, such dispersions are likely to widen. As reported in the policy brief by Fielding, there has not been much convergence in the other convergence criteria over time, particularly Capital Spending, Public Wages, External Deficits and Tax Revenues.

\footnotetext{
${ }^{19}$ Source: What can the European Central Bank Learn from Africa? in Policy Brief, written by David Fielding, United Nations University (November, 2005).
} 


\subsection{Optimum Currency Area}

The basic theory for an Optimum Currency Area (OCA) suggests that for the arrangement in a monetary union to be considered as optimum, the following should hold: (i) the region should not be subject to asymmetric shocks; (ii) there should be a high degree of capital and labor mobility between member states; and (iii) there should be centralized fiscal policy to redistribute tax revenue to poorer countries since country-level monetary policy is not an available option. In this paper, the asymmetries observed in inflation persistence run counter to the first requirement of an OCA, and especially so over the short-term. More focussed attention has been given to this aspect by other research and the jury is still out on the status of the Zone. In fact, we have found no empirical evidence in the literature suggesting that the Franc zone is an OCA. Although a more thorough analysis on the topic will be more conclusive, the results obtained in this paper do not support the view that the current constitution is an optimum arrangement.

Based on our results, a common shock to inflation, which could be due to a central bank policy change, indicate that the effects will die out at some stage, with a transmission lag. However, we have shown that an inflationary shock in a sector is likely to be more persistent in some member states, and not in others. Against this background, the conduct of monetary policy by the central bank should be implemented with full knowledge of some countries' proclivity for persistence. Following some earlier reported research findings on UEMOA economies which indicate that the poor are likely to bear most of the burden of price changes following a monetary policy change, our results suggest that some countries would need some help in order to stabilize their economies following such a shock.

This is the first work, to the author's knowledge, which investigates the presence and degree of persistence in sector-specific inflation in the CFA Franc zone over any period. Furthermore, using three different semi-parametric methods of estimating the degree of inflation persistence and focussing on both food and non-food sectors in these countries, our overall results are made more robust and the findings will prove useful to applied economists and policy makers in the Franc zone as well as other developing countries, particularly countries intending to form monetary unions across Africa regarding the determination and design of new policies for their respective monetary unions.

\section{Concluding Remarks}

Previous research analyzing asymmetries in inflation dynamics across Africa is limited. However, even more limited is the literature on asymmetries in sector-specific inflation dynamics across member-states of the Franc zone. Recently, Fielding (2004) showed that some asymmetries exist across member states of the West-African group of the Franc zone vis-à-vis the short-run response to monetary policy changes, particularly related to different hypothetical income groups. Bamba (2005), investigating the speed of nominal convergence in the West-African group of the Franc zone, also finds significant crosscountry asymmetries in convergence performance existing between member-states; and episodes of convergence are rather short-lived. 
Using three semi-parametric methods of estimating the fractional integration parameter, as proposed by Geweke and Porter-Hudak (1983), Phillips (1999a,b) and Robinson (1995) respectively, our results are consistent with the view that some asymmetry in inflation dynamics exist among member states. Analyzing persistence in food and non-food price inflation across 13 members of the Franc zone, this paper establishes the following: (i) stationarity in inflation is indeed a feature of the Franc zone; (ii) some evidence of persistence exists in the non-food sector of Cameroon, Chad, Gabon, Niger and Senegal; (iii) Chad, Equatorial Guinea and Niger also show some significant evidence of persistence in food price inflation. However, in the case of Equatorial Guinea the evidence is in favor of what is termed anti-persistence rather than long-memory; and shocks do not persist as in Chad and Niger. Results for the food sector in Benin and Togo are not as robust, due to inconsistent evidence on statistical significance of estimates provided by the different methods. It can be argued here that the 'weaker' member-states are more prone to persistence in inflation, as exemplified by Chad and Niger's seeming susceptibility to persistence in both sectors. Although further categorization may be achieved even among member states that do not exhibit inflation persistence (as in Gadea and Mayoral, 2006), the purpose of this study is to identify two groups - where inflation persistence exists, and where it does not).

These results suggest that policy makers in the Franc zone, and particularly the abovementioned countries, may need to anticipate the dynamics of sector-specific inflation rates following a shock such as a major change in monetary policy or oil price levels. This is because shocks in sector-specific inflation seem to have a longer-term effect in some member-states than in others, which is likely to lead to a higher burden being borne by those who spend a higher proportion of their income on the sector experiencing the persistence. Specifically, mitigating national policies may be needed to alleviate possible adverse effects of such unexpected shocks in this subset of member states when implementing the Zone's policy.

Increased knowledge about idiosyncratic dynamics of inflation in the monetary union implies that short and long-term forecasts of both food and non-food price inflation rates can be improved, which is instrumental in successful implementation of any deflationary policy and is particularly relevant in cases of inflation targeting. However, the performance of inflation forecasting is beyond the scope of this paper and is not considered here. Baum et al. (1999c) suggest, using US data, that monetary aggregates exhibit long-memory property which will be transmitted to inflation, given the dependence of long-run inflation on the growth rate of money. An analysis of persistence in the various components of the money stock in the Franc zone, particularly policy instruments, is likely to yield some useful information, and better inform policy decisions, regarding the source of observed persistence in inflation. This will form the basis of future research. 


\section{APPENDIX}

\section{A Brief Description of Fractional Integration Meth- ods}

Spectral Regression approach, Geweke and Porter-Hudak (1983): The Spectral Regression approach put forward by Geweke and Porter-Hudak (1983) [hereafter $\mathrm{GPH}]$ proposes a regression of the form:

$$
\ln I\left(\xi_{\gamma}\right)=\alpha_{0}+\alpha_{1} \ln 4 \sin ^{2}\left(\frac{\xi_{\gamma}}{2}\right)+\eta_{\gamma}
$$

$\gamma=1,2, \ldots, v$, and $I\left(\xi_{\gamma}\right)$ is the periodogram of the time-series at the Fourier frequencies of the sample $\xi_{\gamma}=\frac{2 \pi \gamma}{T} ;(\gamma=1,2, \ldots,((T-1) / 2)), T$ being the number of observations, and the number of Fourier frequencies included in the spectral regression is $\gamma=G(T)<<T$. Therefore assuming that $\lim _{T \rightarrow \infty} G(T)=\infty$, then $\lim _{T \rightarrow \infty} \frac{G(T)}{T}=0$ and $\lim _{T \rightarrow \infty} \frac{\ln (T)^{2}}{G(T)}=0$, the estimate of the fractional differencing parameter, according to GPH, is based on the slope of the spectral density function around the angular frequency $\xi=0$. This parameter of interest (the fractional-differencing parameter, $d$ ), may now be estimated as the negative of the slope coefficient in Equation 5. By their method, GPH prove consistency and asymptotic normality for $d<0$, but not for estimates of $d>1$.

Modified Spectral Regression approach, Phillips (1999a,b): In view of the inconsistency of the GPH when $d>1$, it is unsuitable for testing the null of $d=1$. In the Modified Spectral Regression approach, Phillips (1999a,b) improve on this inconsistency (a short-fall of GPH approach) and provide an estimate of $d$ by proposing a modification of the dependent variable to reflect the distribution of $d$ under the null hypothesis that $d=1$. As for conventional unit-root tests, when there are deterministic trends in the model it is desirable that they are extracted prior to using this test. By default, a linear trend is removed from the series. The Modified Spectral Regression approach is simply a least squares regression of $\ln I\left(\xi_{\gamma}\right)$ on $\ln \left|1-e^{i \xi_{\gamma}}\right|$. Based on the above, Phillips (1999b) provide the estimate of $d$ as:

$$
d=\frac{1}{2} \cdot \frac{\sum_{\gamma=1}^{v} x_{\gamma} \ln I\left(\xi_{\gamma}\right)}{\sum_{\gamma=1}^{v} x_{\gamma}^{2}}
$$

where $x_{\gamma}=\ln \left|1-e^{i \xi_{\gamma}}\right|-\frac{1}{v} \sum_{\gamma=1}^{v} \ln \left|1-e^{i \xi_{\gamma}}\right|$ and the semi-parametric test for a unit-root against fractional alternatives can be based simply on the statistic and $Z_{d}=\frac{\sqrt{v}(\tilde{d}-1)}{\pi / \sqrt{24}}$, with critical values obtained from the standard normal distribution and the test is consistent against both $d<1$ and $d>1$ fractional alternatives.

Gaussian Semi-parametric, Robinson (1995): The Gaussian Semi-parametric approach proposed by Robinson (1995) estimates a self-similarity parameter $H$, which 
is related to the long-memory parameter $(d)$ such that $H=0.5(2 d+1)$. The spectral density of the the time-series is assumed to behave as follows:

$$
f(\xi) G \xi^{1-2 H}
$$

as $\xi \rightarrow 0^{+}$where $\xi$ is as previously defined for GPH approach above. For $H=0.5$, $f(\xi)$ tends to a finite positive constant at zero frequency. For $H \in(0.5,1), f(\xi)$ tends to infinity, whereas if $H \in(0,0.5), f(\xi)$ tends to zero.

$$
R(H)=\ln \hat{G}(H)-(2 H-1) \frac{1}{\gamma} \sum_{\gamma=1}^{v} \ln \xi_{\gamma}
$$

where $\hat{G}(H)=\frac{1}{\gamma} \Sigma_{\gamma=1}^{v} \xi_{\gamma}^{2 H-1} I\left(\xi_{\gamma}\right)$ and $0 \leq H \leq 1$ (or $-0.5 \leq d \leq 0.5$ ), and $\xi_{\gamma}=\frac{2 \pi \gamma}{T} ; \frac{v}{T} \rightarrow 0$. The estimate for the self-similarity parameter $H$, is obtained through minimizing Equation 8 w.r.t. H. Under finiteness of the fourth moment, Robinson shows the estimator to be $v^{0.5}$, with mean zero and variance $\frac{1}{4 v}$. An important requirement, in asymptotic theory, is that $v$ is assumed to tend to $\infty$ more slowly than $T$. The suggested advantages of the Gaussian Semi-parametric approach with respect to the GPH approach include consistency under mild conditions; also it displays asymptotic normality and increased efficiency under some stronger conditions. While GPH prove consistency and asymptotic normality for $d<0$, Robinson (1995) proves consistency and asymptotic normality for $d \in(0,0.5)$ in the case of Gaussian ARMA innovations in Equation 1. To avoid biasing the estimates, Robinson(1995) suggests that $v$ should be not be more than $0.5 T$ (i.e. $v \leq 0.5 T)$.

Velasco (1999) proposes a novel semi-parametric approach, based on the Gaussian semi-parametric estimation approach by Robinson (1995) for stationary processes. Velasco shows that, even by narrowing the number of observations (say, by trimming out the low frequency ordinates) under Gaussian assumptions and for any degree of nonstationarity $(0.5<d<1)$, the fractionally differencing parameter $(d)$ may still be consistently estimated for the memory of the series.

\section{B Measures of Persistence}

Specifically relating to measuring persistence in economic series, various measures can be used to allow adequate comparison of the series' evolution over time. First, the impulse response function (IRF) visually displays the long-run nature of persistence in a series following a shock. The IRF is known not to die out for unit-root series, but dies out for stationary series (see Andrews and Chen (1994)). However, in comparing levels of persistence, it is often considered more useful to focus on a scaler measure of persistence rather than visually comparing IRFs (which are sometimes difficult to interpret being a vector rather than a scaler, and can look similar). ${ }^{20} \mathrm{~A}$ measure that is directly related

\footnotetext{
${ }^{20}$ Hauser et al. (1999) criticize the use the $\operatorname{ARFIMA}(p, d, q)$ model for measuring persistence, stating that in an ARIMA representation, the ARFIMA model is likely to provide erroneous estimates of $d$. However, this is not a concern of this paper since each of the test results shown in Tables $8-13$ categorically reject $d=1$.
} 
to the IRF, and yet is a scaler measure is the cumulative impulse response (CIR) which is the sum of the IRF across time, which is proportional to the spectral density at zero frequency (see Andrews and Chen (1994)):

$$
C I R=\sum_{t=0}^{\infty} I R F(t)
$$

One obvious disadvantage of the CIR, though, is that in comparing levels of persistence it is not likely to be very informative when the IRF happen to be different in shape. An example is when one is, say, positive at all points and the other oscillates between positive and negative, and yet they sum up to give the same CIR. Generally, the CIR, as a measure of persistence, will also not be able to distinguish between two series in which one exhibits a large initial increase and then a subsequent quick decrease in the IRF while the other exhibits a relatively small initial increase followed by a subsequent slower decrease in the IRF. Secondly, for any fractionally integrated (FI) process WITH $d>0$, the spectral density is unbounded at zero frequency $(\mathrm{CIR}=\infty)$. However, this is not the case when $d=0$. Another related measure of persistence is the sum of the autoregressive $(\mathrm{AR})$ coefficients, say a, in an $\mathrm{AR}(p)$ model, where $C I R=(1 /(1-\alpha))$. Empirical studies including Batini (2002) and Gadzinski and Orlandi (2004) both make use of $\alpha$ in their studies. In some studies it has been suggested that, in $\operatorname{AR}(p)$ models with a time trend, estimation of $\alpha$ using the method of least squares (LS) has a problem of bias. Therefore, instead of using the LS method to obtain $\alpha$, Andrews and Chen (1994) propose a median-unbiased estimation method for $\alpha$ which involves the use of an a that yields a median of the $\alpha_{L S}$ (the a obtained from the least squares method). According to the authors, the $\operatorname{AR}(1)$ case provides an exactly median-unbiased estimator, and an approximately unbiased estimator in the case of the $\operatorname{AR}(p)$ model. Using simulations, they subsequently show that the approximately unbiased estimator is a very good one. Furthermore, in order to obtain the other parameters in the model, the estimate of $\alpha$ is imposed on the model and then and ADF least square regression is run.

In their study, Andrews and Chen (1994) also show that although the magnitude of the largest root in an $\operatorname{AR}(p)$ model is sometimes used as a measure of persistence in the series (see Stock, 1991), it is not very informative. They show that two series having the same dominant root can have different persistence properties since the other roots may differ, and hence may be misleading as a measure of persistence. For example, an $\operatorname{AR}(2)$ process with roots equal to, say, 0.8 and 0.6 will be more persistent than another $\operatorname{AR}(2)$ process with roots of, say, 0.8 and 0.2 . However, using the largest root alone as a measure of persistence, makes them indistinguishable - an argument which holds despite the possibility of computing asymptotically valid confidence intervals for the corresponding estimates.

Another scaler measure of persistence (see Marques (2004) explores the relation between persistence and mean reversion. In this context, the ratio:

$$
\gamma=1-\frac{n}{T}
$$

is proposed as a measure of persistence, where $\mathrm{n}$ represents the number of times the plot of the series crosses the mean during a time interval with $T+1$ observations. Marques shows 
that for a series with zero mean and constant variance, the mean of $\gamma$ is 0.5 , therefore a value of $\gamma \approx 0.5$ is indicative of no (or little) significant persistence (i.e. white-noise behavior). Meanwhile, according to Marques, a value of $\gamma$ significantly greater than 0.5 will be indicative of significant persistence, and a value below 0.5 will signal a negative $\alpha$ (negative long-run autocorrelation). A few important criticisms of this method. First, as is evident in Marques (2004), the mean of the series can be generated in a number of ways - it may be time-varying, constant, or even piece-wise constant - however, the resulting $\gamma$, through $n$, can vary significantly depending on the chosen mean. Second, it is possible that the value of $n$ may be somewhat subjective depending on the properties of the series.

Finally, another measure used in some studies, is the "half-life" statistic, $\tau_{H L}$, which is defined as the number of periods that the IRF remains above 0.5 following a unit shock. Although $\tau_{H L}$ (being measured in units of time) seems a practical measure of persistence, it is easily seen that if the IRF oscillates, then the half-life statistic can understate the persistence of the process. Secondly, even when the IRF is monotonically decaying, the use of $\tau_{H L}$ is likely to be problematic when comparing two different series if one exhibits a faster initial decrease and then a subsequent slower decrease in the IRF than the other. Furthermore, when two IRFs are either both highly persistent (or otherwise), comparison is always problematic as they are often not easily distinguishable.

As noted in the preceding section the autocorrelation function typically exhibits persistence that may be neither consistent with an $\mathrm{I}(1)$ process nor an $\mathrm{I}(0)$ process. Hence, the use of traditional unit-root tests are likely to be overly restrictive and underscore the importance of using long memory and fractionally integrated processes. Section 3.1 of this paper expands on the fractional integration methods applied in this paper.

\section{Structural Break Tests}

1. The Sequential Procedure (hereafter SP) tests for $\iota$ breaks versus $\iota+1$ breaks, hence in this paper, allowing for a maximum of 5 breaks implies $\iota=0, \cdots, 4$. This implies $\iota+1$ tests of the null hypothesis of $\iota$ structural change(s) versus the alternative of $\iota+1$ structural change(s). The test concludes in favour of $\iota+1$ break(s) if the minimal value of the sum of squared residuals in the model with $\iota+1$ break $(s)$ is much smaller than that of the model with ८ break(s).

2. The Bayesian Information Criterion (hereafter BIC) and the modified Schwartz Criterion of Liu, Wu and Zidek, 1997 (hereafter LWZ ). Either information criterion may be used in the selection of the model dimension, which then influences the number of breaks that may be detected. ${ }^{21}$

For each series, the SP (using a 5\% significance level) detects 0 breaks. The other break detection parameters, the BIC and the LWZ also detect 0 breaks in all cases, with the exception of the non-food inflation series for Gabon, Niger and Senegal where

\footnotetext{
${ }^{21}$ See Bai and Perron (2003) for an indepth technical information regarding these tests. All our tests are carried out with a GAUSS program provided by the authors.
} 
BIC detects 2 breaks each whereas the LWZ detected no breaks. Given this seeming disagreement in the number of breaks detected by the BIC and LWZ criteria, we make use of three further tests:

1. The supF tests for 0 breaks versus a fixed number of breaks $(k=1, \cdots, 5)$ - In short, Bai and Perron (2003) describe this test as one that involves a minimization of the global sum of squared residuals or asymptotically equivalent to maximizing the $F$-test.

2. The UDmax tests for 0 breaks versus an unknown number of breaks - An equally weighted version of the test, this statistic is obtained by maximizing the F-test after the estimates of the break points are obtained by the global minimization of the sum of squared residuals for between 1 and $\mathrm{k}$ breaks (i.e. $1 \leq k^{*} \leq k$ ).

3. The WDmax also tests for 0 breaks versus an unknown number of breaks - A weighted version of the test, this statistic is obtained by maximizing the F-test after the estimates of the break points are obtained by the global minimization of the sum of squared residuals for between 1 and $\mathrm{k}$ breaks (i.e. $1 \leq k^{*} \leq k$ ) [See Bai and Perron (2001) for the critical values for different trimming parameters]. 


\section{References}

[1] Amato, J.D. and Laubach, T., 2003. "Rule-of-Thumb Behavior and Monetary Policy", European Economic Review, 47, 791831.

[2] Andrews, D. and Chen, H-Y, 1994. "Approximately Median Unbiased Estimation of Autoregressive Models", Journal of Business and Economic Statistics. 12(2), 187204.

[3] Angeloni, I., Coenen, G. and Smets, F., 2003. "Persistence, the Transmission Mechanism and Robust Monetary Policy", Scottish Journal of Political Economy. 50, 527-549.

[4] Bai, J. and Perron, P., 2003. "Computation and Analysis of Multiple Structural Change Models", Journal of Applied Econometrics. 18, 1-22.

[5] Baillie, R. T., 1996. "Long Memory Processes and Fractional Integration in Econometrics", Journal of Econometrics. 73(1), 5-59.

[6] Baillie, R.T. and Bollerslev, T., 1994. "Cointegration, Fractional Cointegration and Exchange Rate Dynamics", Journal of Finance. 49, 737-45.

[7] Bamba, L. N., 2005. "Analysis of the Convergence Process in the UEMOA Zone", in (Ed.) David Fielding, Macroeconomic Policy in the Franc Zone, Studies in Development Economics and Policy series, Palgrave Macmillan.

[8] Batini, N., 2002. "Euro Area Inflation Persistence", ECB Working Paper. 201. European Central Bank, Frankfurt.

[9] Baum, C.F., Barkoulas, J.T. and Caglayan, M., 1999a. "Long Memory or Structural Breaks: Can Either Explain Nonstationary Real Exchange Rates Under the Current Float?", Journal of International Financial Markets, Institutions and Money. 9, 356-376.

[10] Baum, C.F., Barkoulas, J.T. and Caglayan, M., 1999b. "Persistence in International Inflation Rates", Southern Economic Journal. 65 (4), 900-914.

[11] Baum, C.F., Barkoulas, J.T. and Caglayan, M., 1999c. "Fractional Monetary Dynamics", Applied Economics. 31 (11), 1393-1400.

[12] Benigno, P. and Lopez-Salido, D., 2002. "Inflation Persistence and Optimal Monetary Policy in the Euro Area", ECB Working Paper 178. European Central Bank, Frankfurt.

[13] Coenen, G., 2003. "Inflation Persistence and Monetary Policy Design", ECB Working Paper No. 290. European Central Bank, Frankfurt.

[14] Dahlhaus, R., 1989. "Efficient Parameter Estimation for Self-Similar Process", Annals of Statistics. 17 (6), 1749-1766. 
[15] Easterly, W. and Fisher, S., 2000. "Inflation and the Poor", World Bank (Country Economics Department) Working Paper 2335, Washington DC.

[16] Fielding, D., 2004. "How does Monetary policy Affect the Poor? Evidence from the West African Economic and Monetary Union", Journal of African Economies. 13 (4), 563-593.

[17] Fox, R. and Taqqu, M.S., 1986. "Large-Sample Properties of Parameter Estimates for Strongly Dependent Stationary Gaussian Time Series", Annals of Statistics. 14 (3), 517-32.

[18] Gadea, M. D. and Moyoral, L. 2006. "The Persistence of Inflation in OECD Countries: A Fractionally Integrated Approach, International Journal of Central Banking, 2, 51-104.

[19] Gadzinski, G. and Orlandi, F., 2004. "Inflation Persistence in the European Union and the United States". ECB Working Paper No. 414. European Central Bank, Frankfurt.

[20] Galí, J. and Gertler, M., 1999. "Inflation Dynamics: A Structural Econometric Analysis", Journal of Monetary Economics, 44, 195222.

[21] Geweke, J. and Porter-Hudak, S., 1983. "The Estimation and Application of Long Memory Time Series Models", Journal of Time Series Analysis. 4, 221-238.

[22] Gil-Alaña, L.A. and Robinson, P.M., 1997. "Testing of Unit Roots and Other Nonstationary Hypotheses in Macroeconomic Time Series", Journal of Econometrics. 80, 241-268.

[23] Granger, C. W. J. and Joyeux, R., 1980. "An Introduction to long-memory Time Series Models and Fractional Differencing", Journal of Time Analysis. 1,15-39.

[24] Granger, C. W. J., 1980. "Long memory relationships and the aggregation of dynamic models", Journal of Econometrics. 14(2), 227-238.

[25] Hosking, J. R. M., 1981. "Fractional Differencing", Biometrika. 68, 165-176.

[26] Hauser, M., Poetscher, B. N. and Reschenhofer, E., 1999. "Measuring Persistence in Aggregate Output: ARMA Models, Fractionally integrated ARMA Models and Nonparametric Procedures", Empirical Economics. 24, 243-269.

[27] Levin, A. and Piger, J.M., 2004. "Is Inflation Persistence Intrinsic in Industrial Economies?", ECB Working Paper 334. European Central Bank, Frankfurt.

[28] Levin, A. and Moessner, R., 2005. "Inflation Persistence and Monetary Policy Design", ECB Working Paper 539. European Central Bank, Frankfurt.

[29] Liu, J., Wu S. and Zidek, J. V., 1997. "On segmented multivariate regressions", Statistica Sinica, 7, 497-525. 
[30] Lünnemann, P. and Mathä, T. Y., 2004. "How Persistent is Disaggregate Inflation? An Analysis Across EU15 Countries and HICP sub-Indices", ECB Working Paper No. 415. European Central Bank, Frankfurt.

[31] Marques, C.R., 2004. "Inflation Persistence: Facts or Artefacts?", ECB Working Paper No. 371. European Central Bank, Frankfurt.

[32] Parke, W. R., 1999. "What is Fractional Integration?", The Review of Economics and Statistics. 81 (3), 632-38.

[33] Phillips, P. C. B., 1999a. "Discrete Fourier Transforms of Fractional Processes", Unpublished working paper No. 1243, Cowles Foundation for Research in Economics, Yale University.

[34] Phillips, P. C. B., 1999b. "Unit Root Log Periodogram Regression", Unpublished working paper No. 1244, Cowles Foundation for Research in Economics, Yale University.

[35] Roberts, J. M., 1997. "Is inflation sticky?", Journal of Monetary Economics, 39(4): 176-196.

[36] Robinson, P., 1994. "Efficient Tests of Nonstationary Hypotheses", Journal of the American Statistical Association. 89 (4), 1420-1437.

[37] Robinson, P., 1995. "Gaussian Semi-parametric Estimation of Long-Range Dependence", Annals of Statistics. 23, 1630-1661.

[38] Romer, C.D. and Romer, D. H., 1998. "Monetary Policy and the Well-Being of the Poor", NBER Working Paper 6793, Washington DC.

[39] Sbordone, A., 2002. "Prices and unit labor costs: A New Test of Price Stickiness", Journal of Monetary Economics, 49, 265292.

[40] Sowell, F., 1992. "Maximum Likelihood Estimation of Stationary Univariate Fractionally Integrated Time Series Models", Journal of Econometrics. 53 (1), 165-98.

[41] Stock, J. H. 1991. "Confidence Intervals for the Largest Autoregressive Root in the US Macroeconomic Time Series", Journal of Monetary Economics. 28, 435-459.

[42] Velasco, C., 1999. "Gaussian Semi-parametric Estimation of Nonstationary Time Series", Journal of Time Series Analysis. 20, 87-127. 

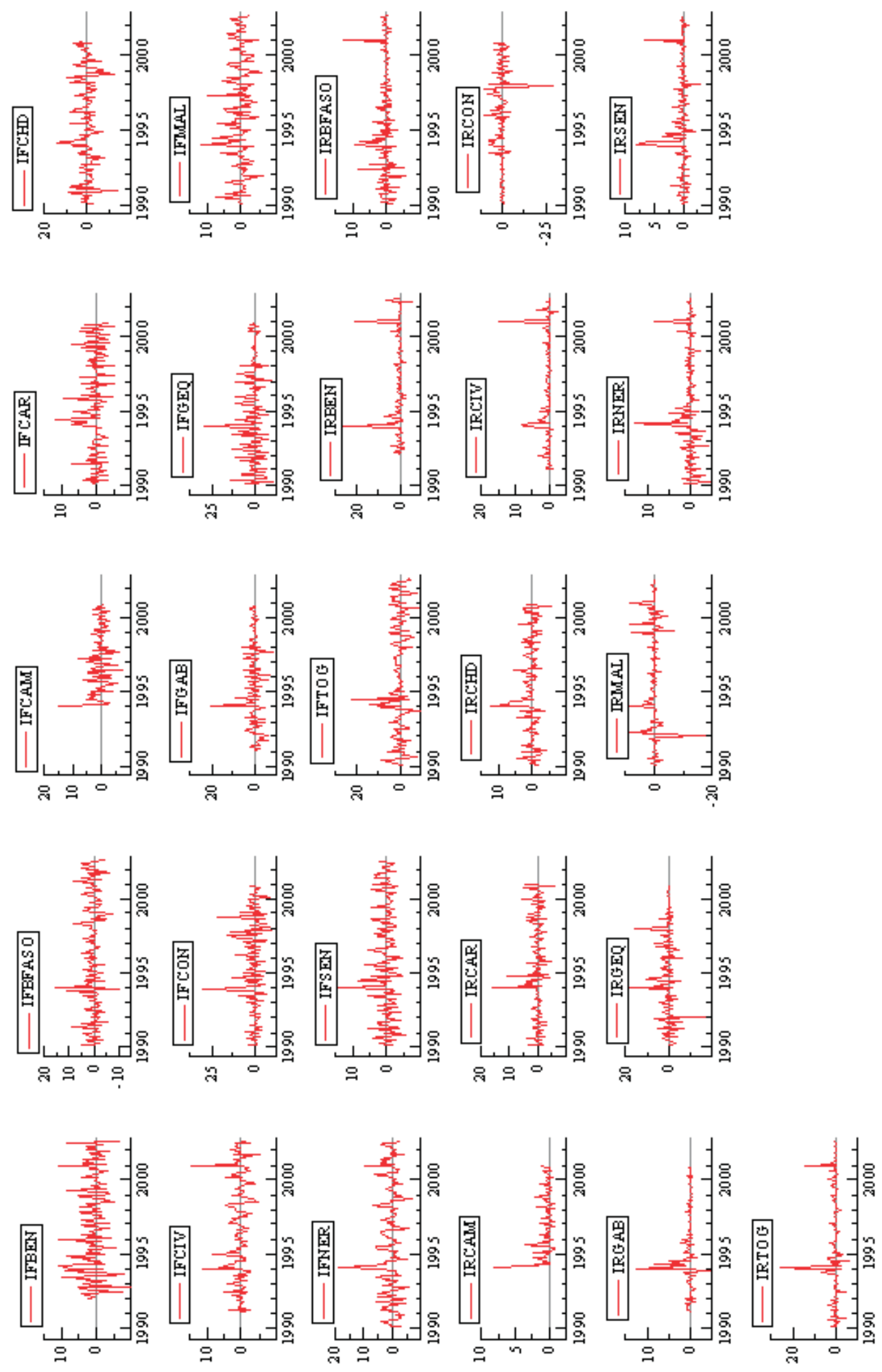

Figure 1: Time Series Plots of Food (IF-) and non-Food (IR-) Price Inflation for Individual member states of the Franc Zone 

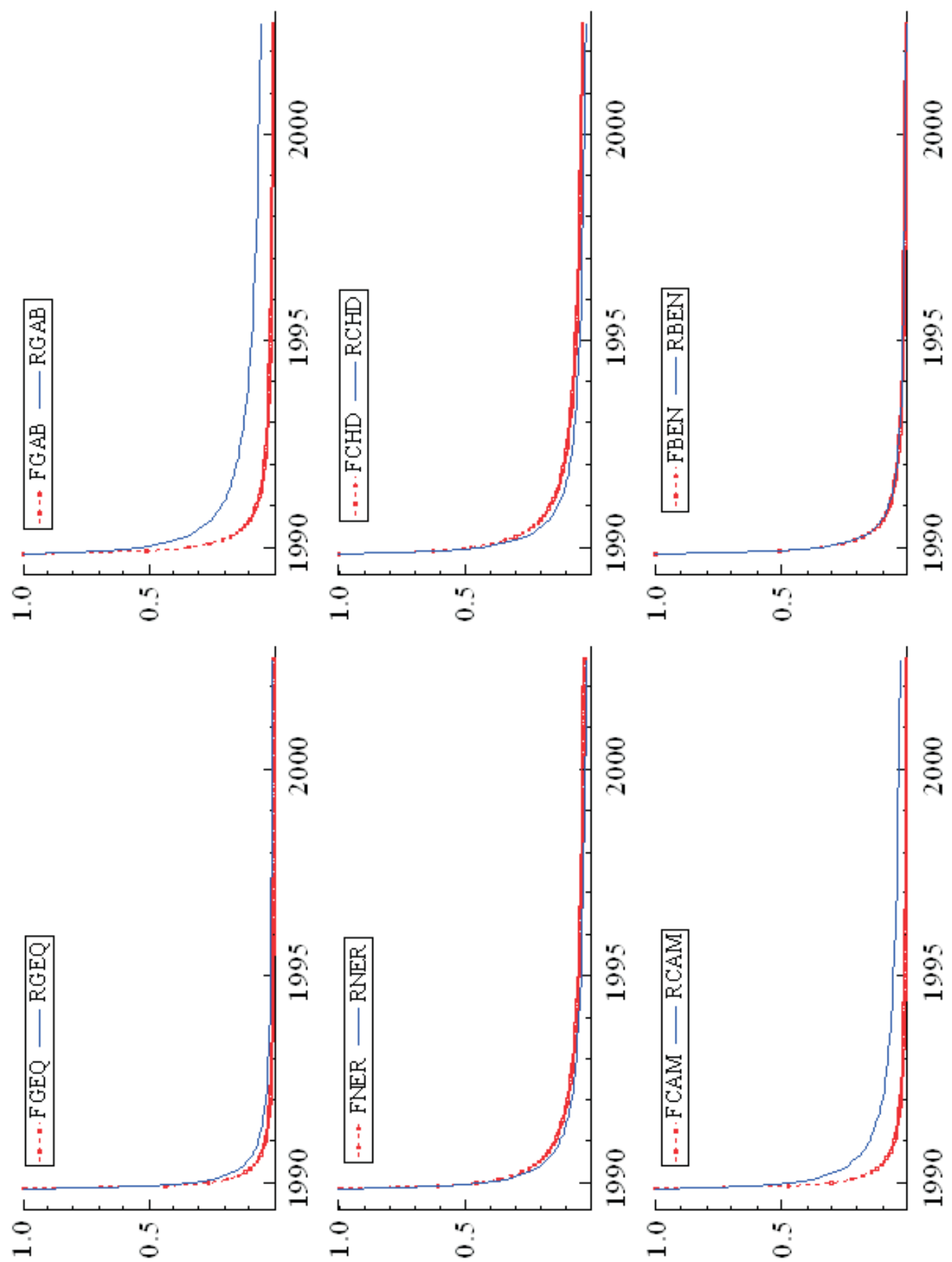

Figure 2: Sector-specific impulse responses for inflation dynamics in selected member states following to a unit shock. [F- and R- Represent Food and non-Food respectively]. 


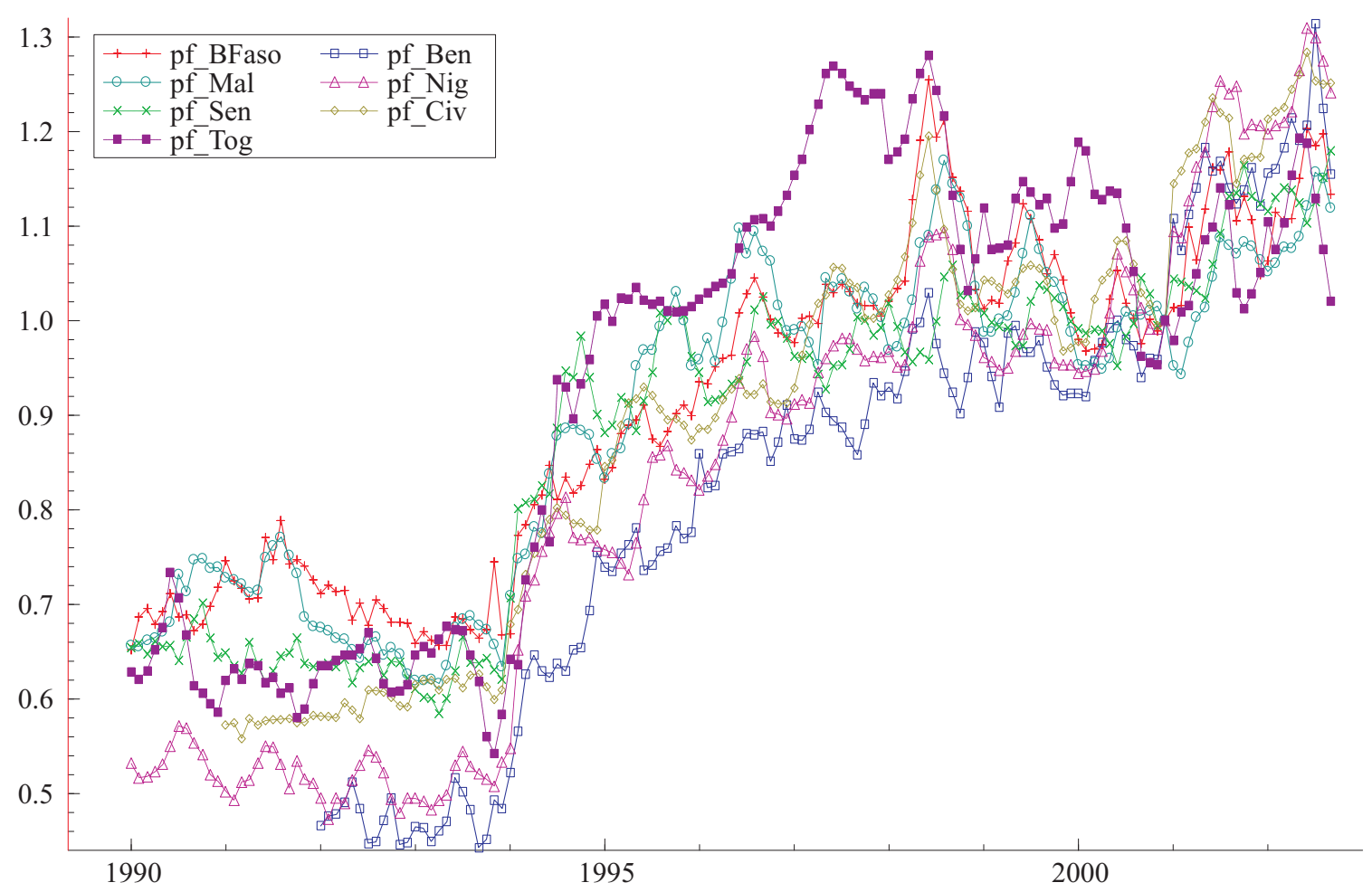

Figure 3: Time series of Food Price dynamics in UEMOA region.

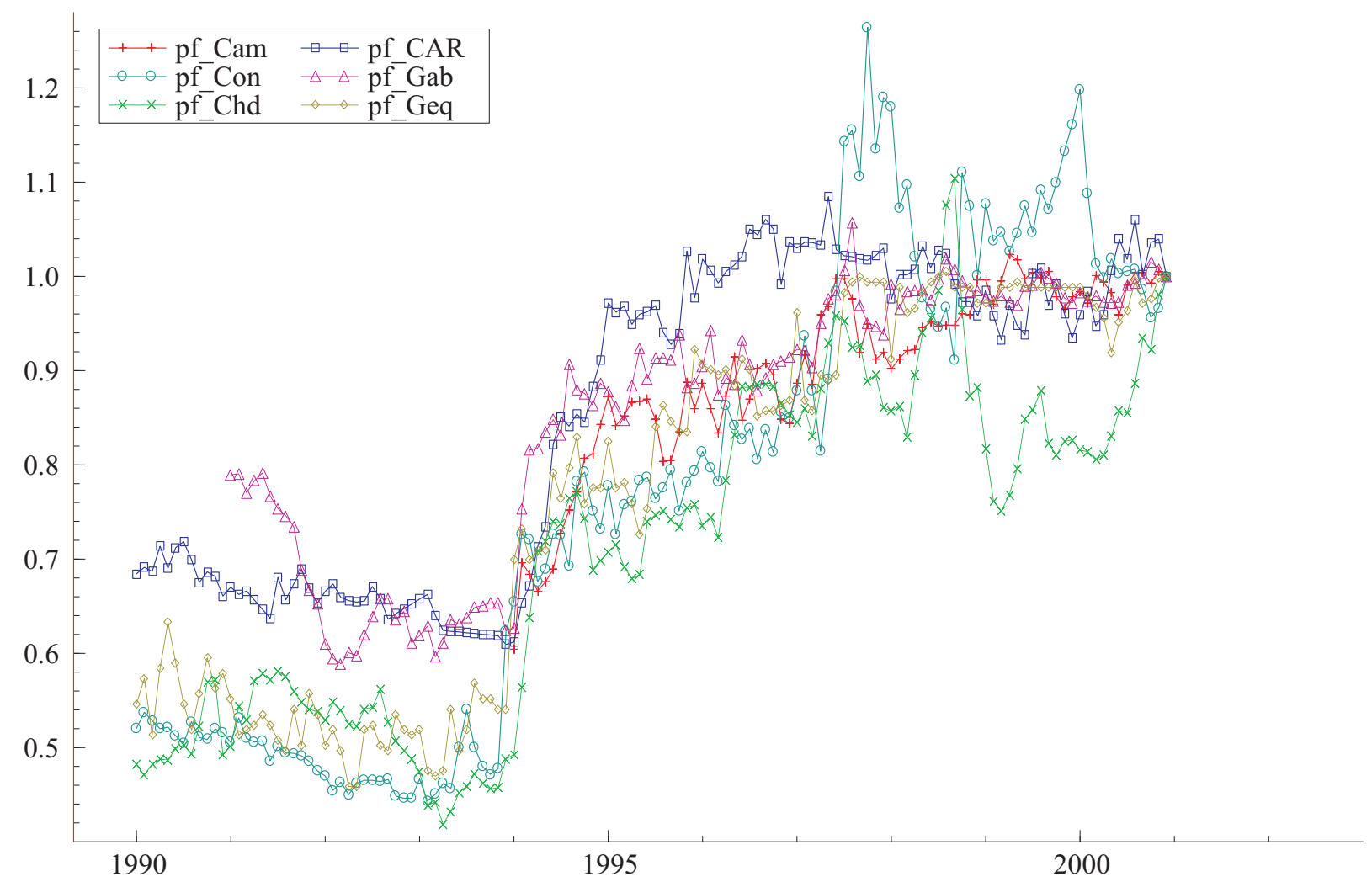

Figure 4: Time series of Food Price dynamics in CEMAC region. 


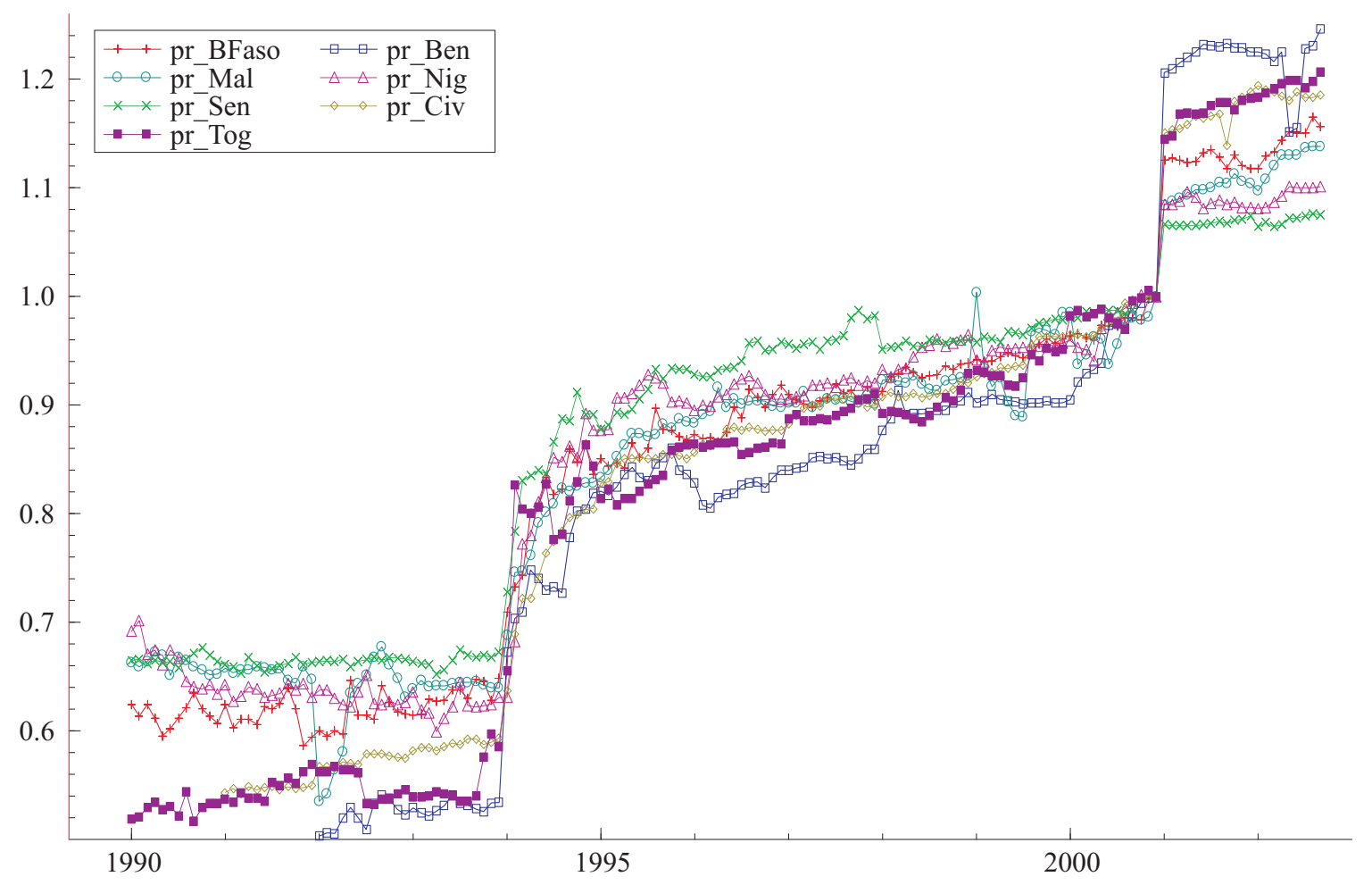

Figure 5: Time series of Non-food Price dynamics in UEMOA region.

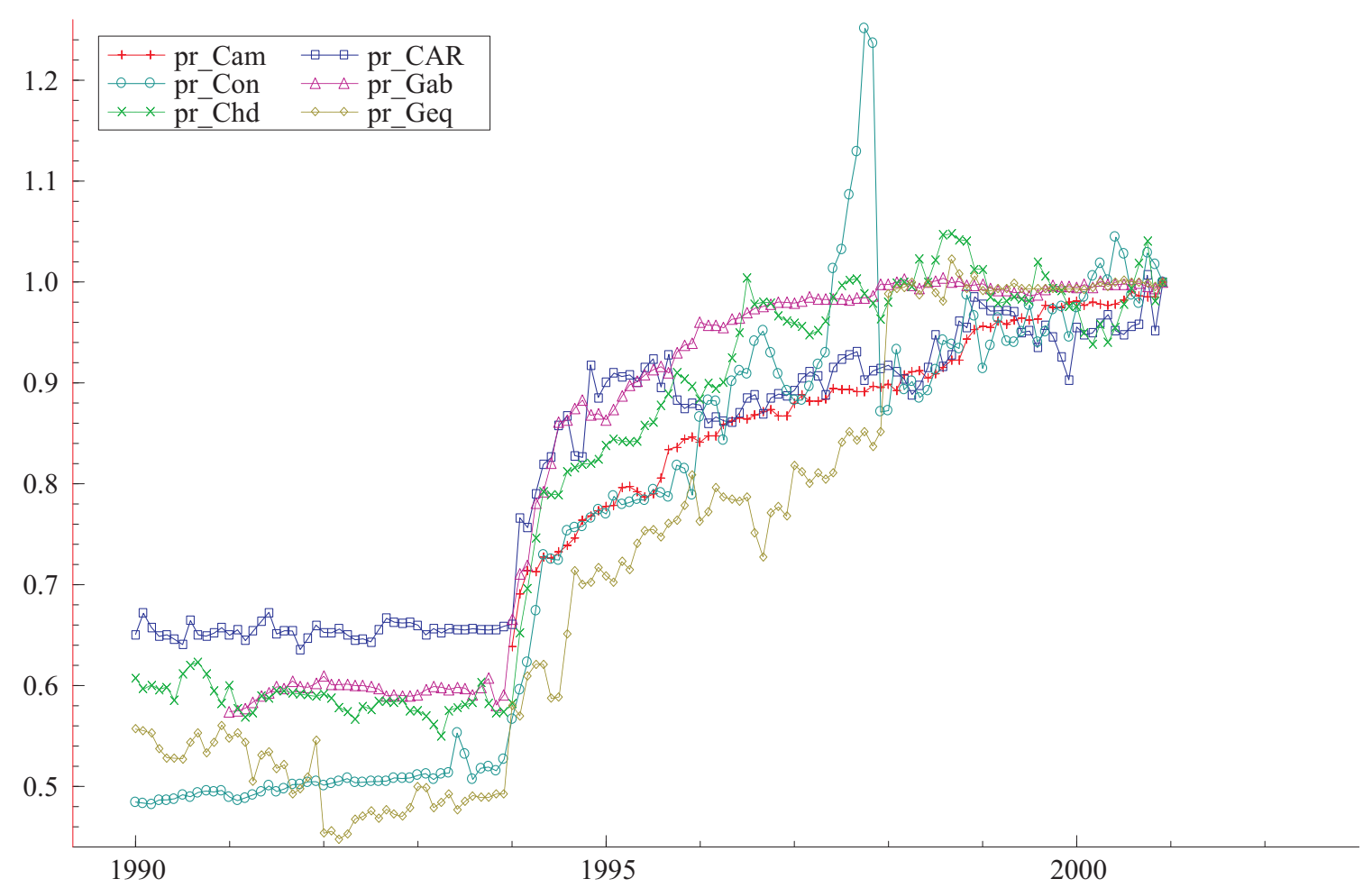

Figure 6: Time series of Non-food Price dynamics in CEMAC region. 
Table 1: Human Development Index (HDI) for Franc Zone Countries, 1975-2003.

\begin{tabular}{lccccccc}
\hline Country & 1975 & 1980 & 1985 & 1990 & 1995 & 2000 & 2003 \\
\hline Ben & 0.304 & 0.336 & 0.362 & 0.368 & 0.395 & 0.422 & 0.431 \\
BFaso & 0.253 & 0.273 & 0.297 & 0.305 & 0.311 & 0.328 & 0.317 \\
Civ & 0.409 & 0.441 & 0.448 & 0.442 & 0.427 & 0.428 & 0.420 \\
Mal & 0.230 & 0.256 & 0.263 & 0.283 & 0.307 & 0.330 & 0.330 \\
Nig & 0.236 & 0.252 & 0.242 & 0.249 & 0.256 & 0.271 & 0.281 \\
Sen & 0.311 & 0.339 & 0.375 & 0.403 & 0.421 & 0.444 & 0.458 \\
Tog & 0.423 & 0.475 & 0.474 & 0.500 & 0.510 & 0.519 & 0.512 \\
Cam & 0.416 & 0.463 & 0.505 & 0.514 & 0.494 & 0.500 & 0.497 \\
CAR & 0.343 & 0.364 & 0.386 & 0.383 & 0.367 & - & 0.355 \\
Chd & 0.269 & 0.271 & 0.311 & 0.335 & 0.344 & 0.359 & 0.341 \\
Con & 0.452 & 0.499 & 0.540 & 0.526 & 0.531 & - & 0.512 \\
Gwq & - & - & 0.483 & 0.500 & 0.518 & 0.641 & 0.655 \\
Gab & - & - & - & - & - & - & 0.635 \\
\hline
\end{tabular}

Source: Human Development Report 2005, United Nations Development Programme (UNDP).

Notes: The index numbers shown in the table, as reported in the Human Development Report, provide an indication of where a country is developmentwise and are based on measures of three key dimensions: Education (Literacy and School Enrolment), Health (Life Expectancy) and Decent standard of living (Income). - indicates unavailable data. 
Table 2: Gross Domestic Product (GDP) for Franc Zone Countries, 1980-2002.

\begin{tabular}{lccccccc}
\hline Country & 1980 & 1985 & 1990 & 1995 & 2000 & 2001 & 2001 \\
\hline Ben & 245.6 & 469.8 & 533.6 & $1,082.9$ & $1,679.6$ & $1,832.06$ & $1,956.9$ \\
BFaso & 272.0 & 663.1 & 850.2 & $1,330.4$ & $1,832.4$ & $2,070.1$ & $2,251.2$ \\
Civ & $2,149.9$ & $3,134.8$ & $2,939.7$ & $4,987.7$ & $7,546.5$ & $7,869.5$ & $8,149.3$ \\
Mal & 300.5 & 554.5 & 673.2 & $1,358.1$ & $1,900.9$ & $2,222.9$ & $2,302.9$ \\
Nig & 536.2 & 657.0 & 677.2 & 947.5 & $1,176.4$ & $1,295.2$ & $1,418.7$ \\
Sen & 740 & 1,331 & 1,556 & 2,435 & 3,332 & 3,571 & 3,720 \\
Tog & 238.4 & 338.2 & 442.5 & 768.6 & 946 & 955.3 & 1,006 \\
Cam & $1,356.2$ & $3,896.0$ & $3,334.2$ & $4,365.5$ & $6,611.0$ & $7,136.7$ & $7,609.3$ \\
CAR & 168.4 & 316.2 & 392.2 & 556.7 & 651.0 & 686.2 & 691.6 \\
Chd & 187.6 & 390.0 & 439.0 & 717.8 & 986.0 & $1,246.0$ & $1,377.0$ \\
Con & 360.4 & 970.8 & 762.1 & $1,056.2$ & $2,309.8$ & $2,060.7$ & $2,118.5$ \\
Geq & 25.6 & 38.1 & 36.3 & 83.0 & 865.5 & $1,302.3$ & $1,523.7$ \\
Gab & 904.2 & $1,500.5$ & $1,620.6$ & $2,474.6$ & $3,511.3$ & $3,176.7$ & $3,464.6$ \\
\hline
\end{tabular}

Source: International Monetary Fund's International Financial Statistics (IFS) database.

Notes: The GDP is given in billions of CFA Francs.

Table 3: Components of the Human Development Index for Franc Zone Countries, 20022003.

\begin{tabular}{|c|c|c|c|c|c|c|c|}
\hline \multirow{2}{*}{ Region } & \multirow[b]{2}{*}{ Country } & \multicolumn{2}{|c|}{$\begin{array}{c}\text { Life } \\
\text { Expectancy }(\mathrm{yrs})\end{array}$} & \multicolumn{2}{|c|}{$\begin{array}{c}\text { Adult } \\
\text { Literacy }(\%)\end{array}$} & \multicolumn{2}{|c|}{$\begin{array}{c}\text { GDP per } \\
\text { capita (US\$) }\end{array}$} \\
\hline & & 2002 & 2003 & 2002 & 2003 & 2002 & 2003 \\
\hline \multirow[t]{8}{*}{ UEMOA } & Ben & 50.7 & 54.0 & 39.8 & 33.6 & 1,070 & 1,115 \\
\hline & BFaso & 45.8 & 47.5 & 12.8 & 12.8 & 1,100 & 1,174 \\
\hline & Civ & 41.2 & 45.9 & 49.7 & 48.1 & 1,520 & 1,476 \\
\hline & G. Bissau & 45.2 & 44.7 & 39.6 & 39.6 & 710 & 711 \\
\hline & Mal & 48.5 & 47.9 & 19.0 & 19.0 & 930 & 994 \\
\hline & Nig & 46.0 & 44.4 & 17.1 & 14.4 & 800 & 835 \\
\hline & Sen & 52.7 & 55.7 & 39.3 & 39.3 & 1,580 & 1,648 \\
\hline & Tog & 49.9 & 54.3 & 59.6 & 53.0 & 1,480 & 1,696 \\
\hline \multirow[t]{6}{*}{ CEMAC } & Cam & 46.8 & 45.8 & 67.9 & 67.9 & 2,000 & 2,118 \\
\hline & CAR & 39.8 & 39.3 & 48.6 & 48.6 & 1,170 & 1,089 \\
\hline & Chd & 44.7 & 43.6 & 45.8 & 25.5 & 1,020 & 1,210 \\
\hline & Con & 48.3 & 52.0 & 82.8 & 82.8 & 980 & 965 \\
\hline & Geq & 49.1 & 43.3 & 84.2 & 84.2 & 30,130 & 19,780 \\
\hline & Gab & 56.6 & 54.5 & 71.0 & 71.0 & 6,590 & 6,397 \\
\hline
\end{tabular}

Source: Human Development Report 2005, United Nations Development Programme (UNDP). 
Table 4: Parameter Values of Fractional Integration.

\begin{tabular}{lccc}
\hline \hline$d$ & Variance & Shock duration & Stationarity \\
\hline$d=0$ & Finite & Short-lived & Stationary \\
$0<d<0.5$ & Finite & Long-lived & Stationary \\
$0.5 \leq d<1$ & Infinite & Long-lived & Nonstationary \\
$d=1$ & Infinite & Infinite & Nonstationary \\
$d>1$ & Infinite & Infinite & Nonstationary \\
\hline
\end{tabular}

Source: Tkacz (2001).

Table 5: Suggested Number of Breaks: BIC, Modified Schwartz Criterion and Sequential Procedure.

\begin{tabular}{lcccccc}
\hline & \multicolumn{3}{c}{ Food } & \multicolumn{4}{c}{ Non-Food } \\
\hline & BIC & LWZ & SP & BIC & LWZ & SP \\
\hline Ben & 0 & 0 & 0 & 0 & 0 & 0 \\
BFaso & 0 & 0 & 0 & 0 & 0 & 0 \\
Civ & 0 & 0 & 0 & 0 & 0 & 0 \\
Mal & 0 & 0 & 0 & 0 & 0 & 0 \\
Nig & 0 & 0 & 0 & 2 & 0 & 0 \\
Sen & 0 & 0 & 0 & 2 & 0 & 0 \\
Tog & 0 & 0 & 0 & 0 & 0 & 0 \\
Cam & 0 & 0 & 0 & 0 & 0 & 0 \\
CAR & 0 & 0 & 0 & 0 & 0 & 0 \\
Con & 0 & 0 & 0 & 0 & 0 & 0 \\
Gab & 0 & 0 & 0 & 2 & 0 & 0 \\
Geq & 0 & 0 & 0 & 0 & 0 & 0 \\
Chd & 0 & 0 & 0 & 0 & 0 & 0
\end{tabular}

Notes: BIC, LWZ and SP represent the Bayesian Information Criterion, Modified Schwartz Criterion of Liu et al. (1997), and Sequential Procedure respectively. The entries in the table represent the suggested number of breaks by the individual break detection measures suggested by Bai and Perron (2003). 
Table 6: SupF Test statistics: Testing for No breaks vrs a Fixed Number of Breaks.

\begin{tabular}{lcccccccccc}
\hline supF Tests & \multicolumn{4}{c}{ Food } & \multicolumn{4}{c}{ Non-Food } \\
\hline 0 Breaks vrs: & 1 & 2 & 3 & 4 & 5 & 1 & 2 & 3 & 4 & 5 \\
\hline Ben & 0.7 & 1.9 & 2.0 & 1.8 & 1.4 & 1.0 & 3.0 & 2.1 & 1.6 & 1.4 \\
BFaso & 1.8 & 3.0 & 3.2 & 2.5 & 2.0 & 2.3 & 2.2 & 1.8 & 1.7 & 1.3 \\
Civ & 2.9 & 4.5 & 4.6 & 3.4 & 1.6 & 3.2 & 4.2 & 3.4 & 2.7 & 2.4 \\
Mal & 1.9 & 3.7 & 3.5 & 3.2 & 2.7 & 3.1 & 3.3 & 2.8 & 2.4 & W3.1 \\
Nig & 3.3 & 3.4 & 3.0 & 2.5 & 2.0 & 7.3 & 4.8 & 3.4 & 2.8 & 2.3 \\
Sen & 3.5 & 2.8 & 2.9 & 2.3 & 1.6 & 7.0 & 3.7 & 2.7 & 2.3 & 1.8 \\
Tog & 3.2 & 4.9 & 4.9 & 3.0 & 2.5 & 3.1 & 1.2 & 1.4 & 1.4 & 0.9 \\
Cam & 1.7 & 1.6 & 2.0 & 1.8 & 1.6 & 3.8 & 4.8 & 4.1 & 3.4 & 3.3 \\
CAR & 2.1 & 4.9 & 3.3 & 2.6 & 2.2 & 1.3 & 1.4 & 1.2 & 1.1 & 0.8 \\
Con & 3.5 & 2.8 & 2.1 & 1.8 & 1.5 & 3.6 & 5.7 & 3.8 & 3.2 & 2.7 \\
Gab & 4.1 & 3.4 & 2.9 & 3.0 & 2.5 & 3.0 & 4.5 & 3.8 & 4.4 & 3.2 \\
Geq & 0.8 & 1.5 & 1.0 & 0.8 & 0.6 & 1.8 & 3.6 & 2.3 & 1.9 & 1.8 \\
Chd & 2.2 & 2.9 & 2.5 & 1.9 & 1.8 & 3.9 & 6.3 & 2.8 & 3.9 & 2.7
\end{tabular}

Notes: Critical values for SupF tests using $5 \%$ significance level are 8.58, 7.22, 5.96, 4.99 and 3.91 for $\mathrm{k}=1,2, . ., 5$ respectively.

Table 7: Dmax and WDmax Test Statistics and Critical Values: Tests Against an Unknown Number of Breaks.

\begin{tabular}{lcccccccc}
\hline supF Tests & \multicolumn{3}{c}{ Food } & \multicolumn{4}{c}{ Non-Food } \\
\hline & UDmax & \multicolumn{3}{c}{ WDmax } & UDmax & \multicolumn{3}{c}{ WDmax } \\
\hline Ben & 2.0 & 2.9 & 3.1 & 3.6 & 3.1 & 3.4 & 3.6 & 4.0 \\
BFaso & 3.1 & 4.3 & 4.6 & 5.1 & 2.3 & 2.8 & 3.0 & 3.4 \\
Civ & 4.5 & 6.1 & 6.5 & 7.3 & 4.2 & 4.8 & 5.2 & 5.9 \\
Mal & 3.7 & 5.4 & 5.9 & 6.7 & 3.4 & 6.3 & 6.8 & 7.8 \\
Nig & 3.4 & 4.1 & 4.3 & 4.9 & 7.3 & 7.3 & 7.3 & 7.3 \\
Sen & 3.4 & 4.1 & 4.3 & 4.9 & 7.3 & 7.3 & 7.3 & 7.3 \\
Tog & 4.9 & 5.5 & 5.9 & 6.5 & 3.1 & 3.1 & 3.1 & 3.1 \\
Cam & 2.0 & 3.2 & 3.5 & 3.9 & 4.8 & 6.7 & 7.2 & 8.2 \\
CAR & 4.9 & 5.5 & 5.8 & 6.4 & 1.4 & 1.7 & 1.9 & 2.1 \\
Con & 3.5 & 3.5 & 3.5 & 3.7 & 5.7 & 6.4 & 6.8 & 7.5 \\
Gab & 4.1 & 5.0 & 5.4 & 6.2 & 4.5 & 6.9 & 7.5 & 8.6 \\
Geq & 1.4 & 1.6 & 1.7 & 1.9 & 3.6 & 4.1 & 4.3 & 4.8 \\
Chd & 2.9 & 3.6 & 3.9 & 4.5 & 6.3 & 7.1 & 7.5 & 8.3 \\
\hline $10 \% c v$ & 7.4 & 8.2 & & & 7.4 & 8.2 & & \\
$5 \% c v$ & 8.9 & & 9.9 & & 8.9 & & 9.9 & \\
$1 \% c v$ & 12.4 & & & 13.8 & 12.4 & & & 13.8 \\
\hline
\end{tabular}

Notes: The UDmax and WDmax test statistics provided in the table are obtained as part of the Bai and Perron (2003) break detection procedure. The 10\%, $5 \%$ and $1 \%$ critical values are presented in the bottom section (last 3 rows) of the table. 
Table 8: Spectral Regression Estimates of the Fractional Differencing Parameter, $d$, for non-Food Price Inflation.

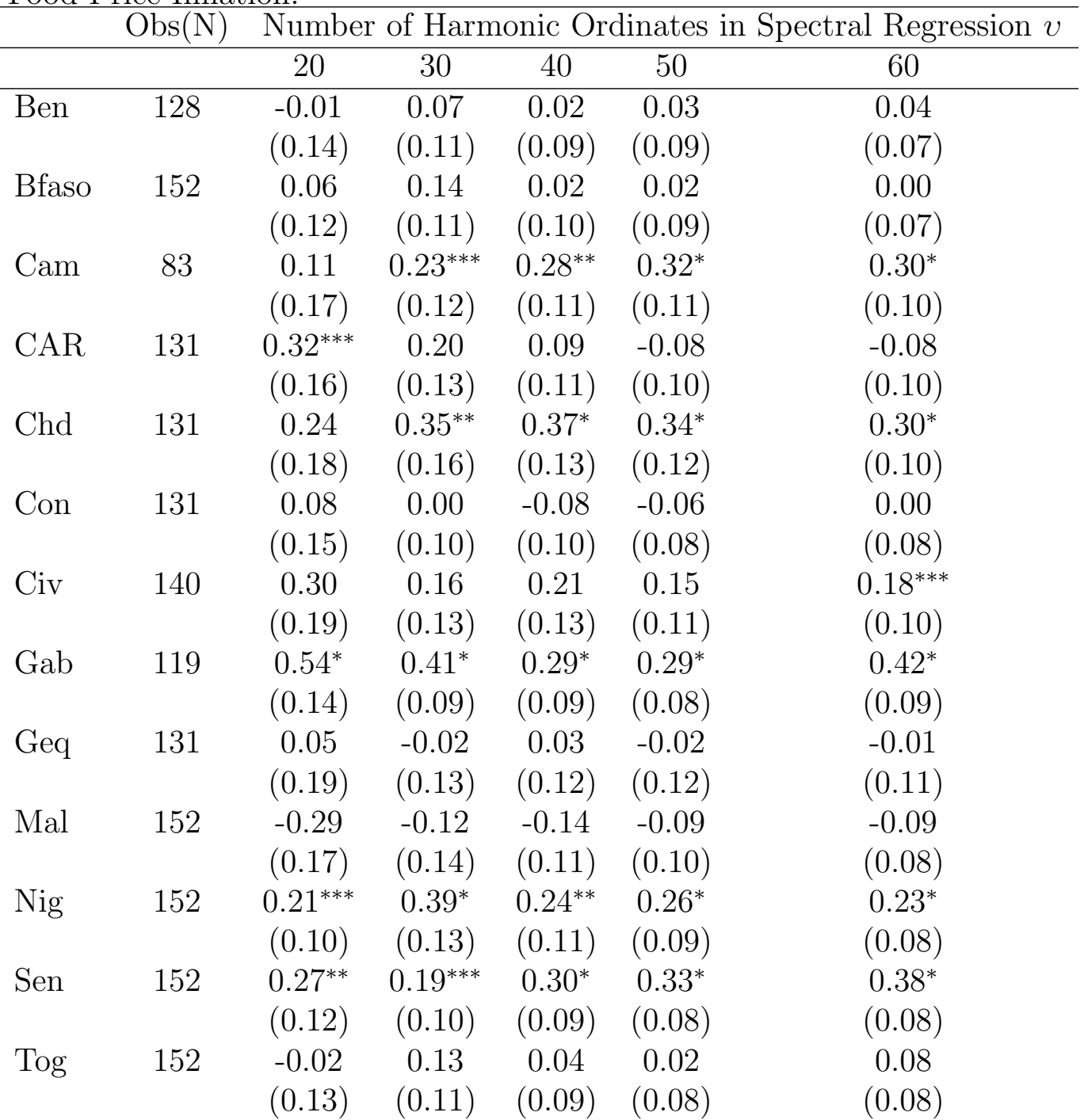

Notes: The estimates of $d$ in this table are found by means of the spectral regression method of Geweke and Porter-Hudak (1983). Number of ordinates $(v)$ indicate the estimation sample size of the spectral regression. Figures in parentheses indicate the conventional standard error of the fractional differencing parameter $d$; and ${ }^{*} ;{ }^{* *} ;{ }^{* * *}$ indicate rejection of the null $(\mathrm{H} 0: d=0)$ at $1 \%, 5 \%$ and $10 \%$ level of significance respectively. 
Table 9: The Modified Spectral Regression Estimates of the Fractional Differencing Parameter, $d$, for non-Food Price Inflation.

\begin{tabular}{|c|c|c|c|c|c|c|}
\hline & $\operatorname{Obs}(\mathrm{N})$ & Numbc & of Har & Ionic $\mathrm{O}$ & dinates & al Regression $v$ \\
\hline & & 20 & 30 & 40 & 50 & 60 \\
\hline Ben & 128 & -0.02 & 0.06 & 0.04 & 0.04 & 0.06 \\
\hline & & $(0.14)$ & $(0.10)$ & $(0.08)$ & $(0.08)$ & $(0.08)$ \\
\hline Bfaso & 152 & 0.10 & 0.15 & 0.03 & 0.02 & 0.00 \\
\hline & & $(0.13)$ & $(0.13)$ & $(0.10)$ & $(0.09)$ & $(0.08)$ \\
\hline Cam & 83 & 0.18 & $0.28^{* *}$ & $0.29^{* *}$ & $0.32^{*}$ & $0.30^{*}$ \\
\hline & & $(0.19)$ & $(0.13)$ & $(0.12)$ & $(0.11)$ & $(0.10)$ \\
\hline CAR & 131 & $0.61^{*}$ & $0.41^{*}$ & $0.27^{* *}$ & 0.08 & 0.08 \\
\hline & & $(0.14)$ & $(0.14)$ & $(0.12)$ & $(0.10)$ & $(0.10)$ \\
\hline Chd & 131 & 0.25 & $0.39^{* *}$ & $0.43^{*}$ & $0.33^{* *}$ & $0.31^{*}$ \\
\hline & & $(0.20)$ & $(0.17)$ & $(0.14)$ & $(0.13)$ & $(0.11)$ \\
\hline Con & 131 & 0.16 & 0.07 & -0.03 & 0.00 & 0.04 \\
\hline & & $(0.14)$ & $(0.10)$ & $(0.10)$ & $(0.08)$ & $(0.08)$ \\
\hline $\mathrm{Civ}$ & 140 & 0.13 & 0.05 & 0.15 & 0.09 & 0.11 \\
\hline & & $(0.19)$ & $(0.13)$ & $(0.13)$ & $(0.11)$ & $(0.10)$ \\
\hline Gab & 119 & $0.52^{*}$ & $0.40^{*}$ & $0.26^{*}$ & $0.31^{*}$ & $0.42^{*}$ \\
\hline & & $(0.14)$ & $(0.10)$ & $(0.09)$ & $(0.09)$ & $(0.09)$ \\
\hline Geq & 131 & -0.01 & -0.05 & 0.00 & 0.00 & -0.01 \\
\hline & & $(0.19)$ & $(0.13)$ & $(0.12)$ & $(0.12)$ & $(0.11)$ \\
\hline Mal & 152 & -0.25 & -0.14 & -0.14 & -0.10 & -0.06 \\
\hline & & $(0.16)$ & $(0.13)$ & $(0.10)$ & $(0.10)$ & $(0.09)$ \\
\hline Nig & 152 & 0.17 & $0.36^{* *}$ & $0.23^{* *}$ & $0.27^{*}$ & $0.23^{*}$ \\
\hline & & $(0.10)$ & $(0.13)$ & $(0.11)$ & $(0.09)$ & $(0.08)$ \\
\hline Sen & 152 & 0.18 & $0.19^{* * * *}$ & $0.26^{* *}$ & $0.33^{*}$ & $0.36^{*}$ \\
\hline & & $(0.14)$ & $(0.11)$ & $(0.09)$ & $(0.09)$ & $(0.08)$ \\
\hline Tog & 152 & -0.01 & 0.15 & 0.03 & 0.03 & 0.08 \\
\hline & & $(0.11)$ & $(0.10)$ & $(0.09)$ & $(0.08)$ & $(0.07)$ \\
\hline
\end{tabular}

Notes: The estimates of $d$ in this table are found by means of the spectral regression method of

Phillips (1999a,b). Number of ordinates $(v)$ indicate the estimation sample size of the spectral regression. Figures in parentheses indicate the conventional standard error of the fractional differencing parameter $d$; and $* * * * * * *$ indicate rejection of the null $(\mathrm{H} 0: d=0)$ at $1 \%, 5 \%$ and $10 \%$ level of significance respectively. Furthermore, in all cases, we can reject the null (H0: $d=1)$ at the $1 \%$ level of significance. 
Table 10: The Gaussian Semi-parametric Regression Estimates of the Fractional Differencing Parameter, $d$, for non-Food Price Inflation.

\begin{tabular}{|c|c|c|c|c|c|c|}
\hline & $\operatorname{Obs}(\mathrm{N})$ & Numbe & of Harr & onic Or & linates $\mathrm{i}$ & al Regression $v$ \\
\hline & & 20 & 30 & 40 & 50 & 60 \\
\hline Ben & 128 & -0.03 & 0.06 & 0.03 & 0.03 & 0.05 \\
\hline & & $(0.13)$ & $(0.10)$ & $(0.08)$ & $(0.08)$ & $(0.07)$ \\
\hline Bfaso & 152 & 0.05 & 0.12 & 0.01 & 0.00 & -0.01 \\
\hline & & $(0.11)$ & $(0.11)$ & $(0.09)$ & $(0.08)$ & $(0.07)$ \\
\hline Cam & 83 & 0.12 & & & & \\
\hline & & $(0.15)$ & & & & \\
\hline CAR & 131 & $0.33^{* * *}$ & 0.16 & 0.06 & -0.10 & -0.09 \\
\hline & & $(0.15)$ & $(0.13)$ & $(0.10)$ & $(0.09)$ & $(0.08)$ \\
\hline Chd & 131 & 0.22 & $0.35^{* *}$ & $0.40^{*}$ & $0.29^{*}$ & $0.28^{*}$ \\
\hline & & $(0.17)$ & $(0.14)$ & $(0.12)$ & $(0.10)$ & $(0.09)$ \\
\hline Con & 131 & 0.05 & -0.01 & -0.09 & -0.06 & 0.00 \\
\hline & & $(0.14)$ & $(0.10)$ & $(0.09)$ & $(0.08)$ & $(0.07)$ \\
\hline Civ & 140 & 0.26 & 0.13 & 0.21 & 0.13 & 0.14 \\
\hline & & $(0.18)$ & $(0.13)$ & $(0.13)$ & $(0.10)$ & $(0.09)$ \\
\hline Gab & 119 & $0.52^{*}$ & $0.38^{*}$ & $0.24^{*}$ & $0.29^{*}$ & $0.40^{*}$ \\
\hline & & $(0.13)$ & $(0.08)$ & $(0.08)$ & $(0.08)$ & $(0.07)$ \\
\hline Geq & 131 & -0.01 & -0.03 & 0.02 & 0.01 & 0.00 \\
\hline & & $(0.18)$ & $(0.12)$ & $(0.11)$ & $(0.11)$ & $(0.10)$ \\
\hline Mal & 152 & -0.23 & -0.12 & -0.13 & -0.08 & -0.04 \\
\hline & & $(0.17)$ & $(0.13)$ & $(0.10)$ & $(0.09)$ & $(0.08)$ \\
\hline Nig & 152 & 0.18 & $0.35^{* *}$ & $0.22^{* *}$ & $0.26^{*}$ & $0.22^{*}$ \\
\hline & & $(0.10)$ & $(0.13)$ & $(0.10)$ & $(0.09)$ & $(0.08)$ \\
\hline Sen & 152 & $0.23^{* * *}$ & $0.23^{* * *}$ & $0.28^{*}$ & $0.34^{*}$ & $0.35^{*}$ \\
\hline & & $(0.12)$ & $(0.10)$ & $(0.09)$ & $(0.08)$ & $(0.08)$ \\
\hline Tog & 152 & -0.03 & 0.14 & 0.02 & 0.01 & 0.07 \\
\hline & & $(0.12)$ & $(0.10)$ & $(0.08)$ & $(0.07)$ & $(0.07)$ \\
\hline
\end{tabular}

Notes: The estimates of the $d$ parameter is based on Spectral Regression method of Robinson (1995a). Number of ordinates $(v)$ indicate the estimation sample size of the spectral regression. The figures in parentheses indicate the conventional standard error of the fractional differencing parameter $d$; and *; ${ }^{* *} ; * * *$ indicate rejection of the null $\left(H_{0}: \mathrm{d}=0\right)$ at $1 \%, 5 \%$ and $10 \%$ level of significance respectively. 
Table 11: Spectral Regression Estimates of the Fractional Differencing Parameter, $d$, for Food Price Inflation.

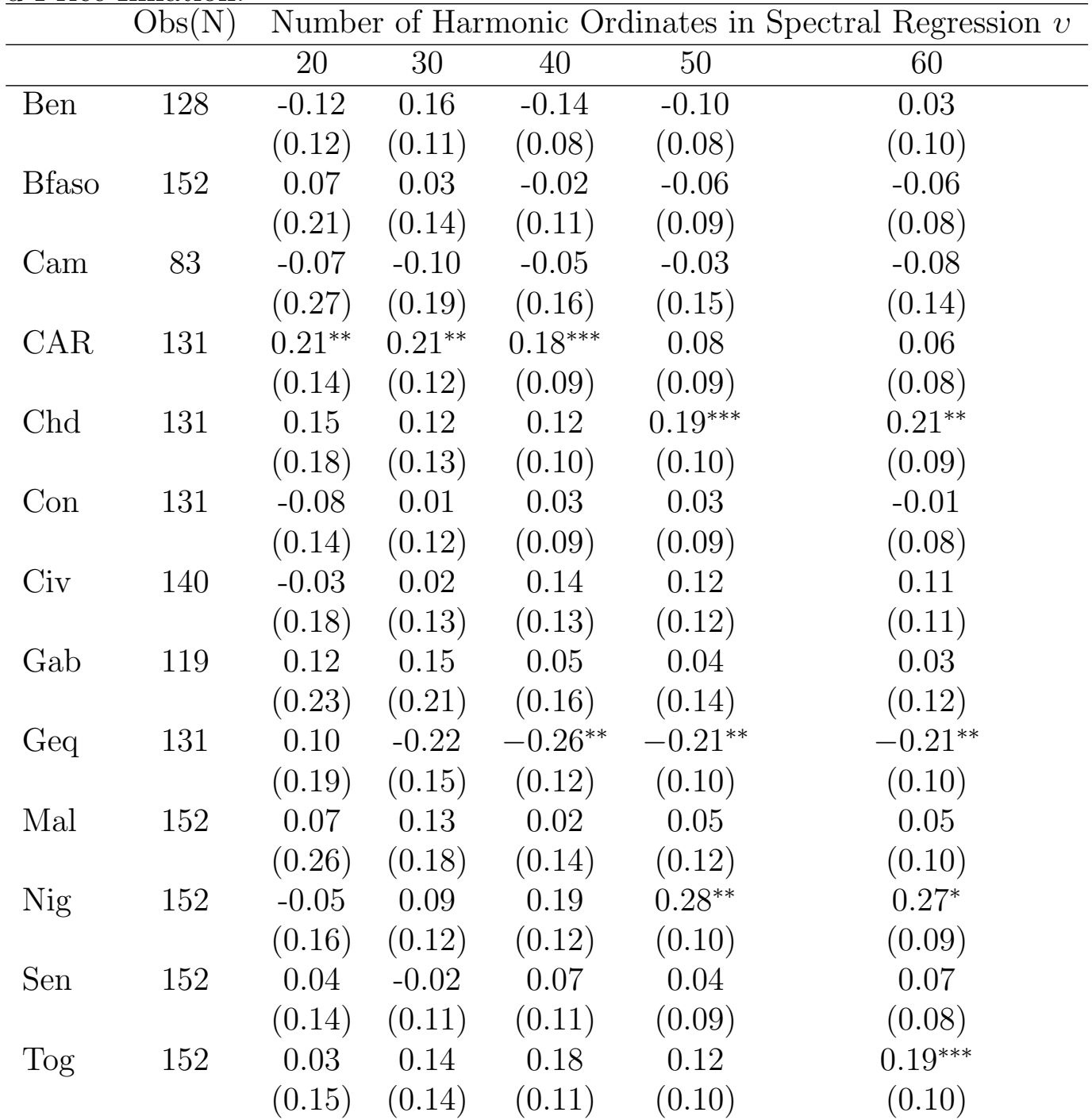

Notes: The estimates of $d$ in this table are found by means of the spectral regression method of Geweke and Porter-Hudak (1983). Number of ordinates $(v)$ indicate the estimation sample size of the spectral regression. Figures in parentheses indicate the conventional standard error of the fractional differencing parameter $d$; and ${ }^{*} ; * * ; * *$ indicate rejection of the null $\left(H_{0}: d=0\right)$ at $1 \%, 5 \%$ and $10 \%$ level of significance respectively. 
Table 12: The Modified Spectral Regression Estimates of the Fractional Differencing Parameter, $d$, for Food Price Inflation.

\begin{tabular}{|c|c|c|c|c|c|c|}
\hline \multirow{2}{*}{\multicolumn{2}{|c|}{$\operatorname{Obs}(\mathrm{N})$}} & \multicolumn{5}{|c|}{ Number of Harmonic Ordinates in Spectral Regression $v$} \\
\hline & & 20 & 30 & 40 & 50 & 60 \\
\hline \multirow[t]{2}{*}{ Ben } & \multirow[t]{2}{*}{128} & $0.31^{*}$ & $0.19^{* *}$ & $0.18^{* *}$ & $0.18^{* *}$ & $0.27^{*}$ \\
\hline & & $(0.12)$ & $(0.10)$ & $(0.09)$ & $(0.08)$ & $(0.09)$ \\
\hline \multirow[t]{2}{*}{ Bfaso } & \multirow[t]{2}{*}{152} & $0.53^{* * *}$ & $0.39^{* *}$ & 0.22 & 0.15 & 0.12 \\
\hline & & $(0.27)$ & $(0.18)$ & $(0.15)$ & $(0.12)$ & $(0.11)$ \\
\hline \multirow[t]{2}{*}{ Cam } & \multirow[t]{2}{*}{83} & 0.05 & -0.06 & -0.02 & 0.02 & -0.02 \\
\hline & & $(0.20)$ & $(0.14)$ & $(0.14)$ & $(0.14)$ & $(0.13)$ \\
\hline \multirow{2}{*}{ CAR } & \multirow[t]{2}{*}{131} & $0.40^{* *}$ & $0.32^{* *}$ & $0.25^{* *}$ & 0.13 & 0.09 \\
\hline & & $(0.15)$ & $(0.12)$ & $(0.10)$ & (0.09) & $(0.09)$ \\
\hline \multirow[t]{2}{*}{ Chd } & \multirow[t]{2}{*}{131} & 0.24 & $0.21^{* * *}$ & 0.17 & $0.22^{* *}$ & $0.26^{*}$ \\
\hline & & $(0.16)$ & $(0.12)$ & $(0.10)$ & $(0.10)$ & $(0.09)$ \\
\hline \multirow[t]{2}{*}{ Con } & \multirow[t]{2}{*}{131} & -0.04 & 0.04 & 0.03 & 0.05 & -0.01 \\
\hline & & $(0.15)$ & $(0.11)$ & $(0.09)$ & $(0.09)$ & $(0.08)$ \\
\hline \multirow[t]{2}{*}{$\mathrm{Civ}$} & \multirow[t]{2}{*}{140} & -0.06 & -0.03 & 0.09 & 0.09 & 0.17 \\
\hline & & $(0.17)$ & $(0.13)$ & $(0.13)$ & $(0.12)$ & $(0.10)$ \\
\hline \multirow[t]{2}{*}{ Gab } & \multirow[t]{2}{*}{119} & 0.06 & 0.17 & 0.02 & 0.04 & 0.01 \\
\hline & & $(0.23)$ & $(0.23)$ & $(0.18)$ & $(0.15)$ & $(0.13)$ \\
\hline \multirow[t]{2}{*}{ Geq } & \multirow[t]{2}{*}{131} & 0.03 & -0.24 & $-0.26^{* *}$ & $-0.23^{* *}$ & $-0.22^{* *}$ \\
\hline & & $(0.19)$ & $(0.15)$ & $(0.12)$ & $(0.10)$ & $(0.10)$ \\
\hline \multirow[t]{2}{*}{ Mal } & \multirow[t]{2}{*}{152} & 0.19 & 0.18 & 0.09 & 0.11 & 0.13 \\
\hline & & $(0.22)$ & $(0.16)$ & $(0.13)$ & $(0.11)$ & $(0.09)$ \\
\hline \multirow[t]{2}{*}{ Nig } & \multirow[t]{2}{*}{152} & 0.14 & $0.31^{* * *}$ & $0.30^{* *}$ & $0.36^{* *}$ & $0.34^{*}$ \\
\hline & & $(0.16)$ & $(0.15)$ & $(0.11)$ & $(0.10)$ & (0.09) \\
\hline \multirow[t]{2}{*}{ Sen } & \multirow[t]{2}{*}{152} & 0.13 & 0.06 & 0.14 & 0.09 & 0.13 \\
\hline & & $(0.13)$ & $(0.11)$ & $(0.12)$ & $(0.10)$ & $(0.08)$ \\
\hline \multirow[t]{2}{*}{ Tog } & \multirow[t]{2}{*}{152} & $0.36^{* * *}$ & $0.39^{* *}$ & $0.30^{* *}$ & $0.24^{* *}$ & $0.29^{*}$ \\
\hline & & $(0.19)$ & $(0.16)$ & $(0.13)$ & $(0.10)$ & $(0.09)$ \\
\hline
\end{tabular}

Notes: The estimates of $d$ in this table are found by means of the spectral regression method of

Phillips (1999a,b). Number of ordinates $(v)$ indicate the estimation sample size of the spectral regression. Figures in parentheses indicate the conventional standard error of the fractional differencing parameter $d$; and $* * * * * * *$ indicate rejection of the null $\left(H_{0}: d=0\right)$ at $1 \%, 5 \%$ and $10 \%$ level of significance respectively. Furthermore, in all cases, we can reject the null (H0: $d=1)$ at the $1 \%$ level of significance. 
Table 13: The Gaussian Semiparametric Regression Estimates of the Fractional Differencing Parameter, $d$, for Food Price Inflation.

\begin{tabular}{|c|c|c|c|c|c|c|}
\hline & $\overline{\operatorname{Obs}(\mathrm{N})}$ & Numbe & of Harms & nic Ordir & ates in $\mathrm{Sp}$ & Regression $v$ \\
\hline & & 20 & 30 & 40 & 50 & 60 \\
\hline Ben & 128 & -0.10 & 0.15 & -0.11 & -0.06 & 0.06 \\
\hline & & $(0.11)$ & $(0.10)$ & $(0.08)$ & $(0.08)$ & $(0.09)$ \\
\hline Bfaso & 152 & 0.02 & 0.05 & -0.04 & -0.05 & 0.06 \\
\hline & & $(0.20)$ & $(0.13)$ & $(0.10)$ & $(0.08)$ & $(0.07)$ \\
\hline Cam & 83 & -0.04 & & & & \\
\hline & & $(0.26)$ & & & & \\
\hline CAR & 131 & $0.28^{* *}$ & $0.22^{* *}$ & $0.18^{* *}$ & 0.06 & 0.03 \\
\hline & & $(0.11)$ & $(0.09)$ & $(0.09)$ & $(0.08)$ & $(0.07)$ \\
\hline Chd & 131 & 0.14 & 0.13 & 0.10 & $0.17^{* * *}$ & $0.21^{* *}$ \\
\hline & & $(0.17)$ & $(0.12)$ & $(0.10)$ & $(0.09)$ & $(0.08)$ \\
\hline Con & 131 & -0.06 & 0.03 & 0.02 & 0.04 & -0.02 \\
\hline & & $(0.13)$ & $(0.11)$ & $(0.09)$ & $(0.08)$ & $(0.07)$ \\
\hline $\mathrm{Civ}$ & 140 & 0.02 & 0.02 & 0.13 & 0.12 & 0.08 \\
\hline & & $(0.18)$ & $(0.12)$ & $(0.12)$ & $(0.11)$ & $(0.09)$ \\
\hline Gab & 119 & 0.09 & 0.16 & 0.01 & 0.03 & 0.00 \\
\hline & & $(0.22)$ & $(0.20)$ & $(0.15)$ & $(0.12)$ & $(0.10)$ \\
\hline Geq & 131 & 0.03 & $-0.24^{* * *}$ & $-0.26^{* *}$ & $-0.22^{* *}$ & $-0.20^{* *}$ \\
\hline & & $(0.19)$ & $(0.14)$ & $(0.11)$ & $(0.09)$ & $(0.09)$ \\
\hline Mal & 152 & 0.06 & 0.09 & 0.00 & 0.03 & 0.05 \\
\hline & & $(0.25)$ & $(0.17)$ & $(0.14)$ & $(0.11)$ & $(0.09)$ \\
\hline Nig & 152 & -0.03 & 0.19 & $0.21^{* * *}$ & $0.28^{*}$ & $0.25^{*}$ \\
\hline & & $(0.15)$ & $(0.15)$ & $(0.11)$ & $(0.09)$ & $(0.08)$ \\
\hline Sen & 152 & 0.02 & -0.01 & 0.06 & 0.03 & 0.08 \\
\hline & & $(0.13)$ & $(0.11)$ & $(0.10)$ & $(0.09)$ & $(0.08)$ \\
\hline Tog & 152 & 0.05 & 0.18 & 0.16 & 0.12 & $0.18^{* *}$ \\
\hline & & $(0.14)$ & $(0.13)$ & $(0.11)$ & $(0.09)$ & $(0.09)$ \\
\hline
\end{tabular}

Notes: The estimates of the $d$ parameter is based on Spectral Regression method of Robinson (1995a). Number of ordinates $(v)$ indicate the estimation sample size of the spectral regression. The figures in parentheses indicate the conventional standard error of the fractional differencing parameter $d$; and *; $* * ; * *$ indicate rejection of the null $(\mathrm{H} 0: d=0)$ at $1 \%, 5 \%$ and $10 \%$ level of significance respectively. 


\section{DISCUSSION PAPERS I N ECONOMI CS}

2008/15 Juan Carlos Cuestas and Paulo Regis, Nonlinearities and the order of integration of order prices

2008/14 Peter Dawson and Stephen Dobson, The influence of social pressure and nationality on individual decisions: evidence from the behaviour of referees

2008/13 Juan Carlos Cuestas and Barry Harrison, Testing for stationarity of inflation in Central and Eastern European Countries

2008/12 Juan Carlos Cuestas and Dean Garratt, Is real GDP per capita a stationary process? Smooth transitions, nonlinear trends and unit root testing

2008/11 Antonio Rodriguez Andres and Carlyn Ramlogan-Dobson, Corruption, privatisation and the distribution of income in Latin America

2008/10 Stephen Dobson and Carlyn Ramlogan, Is there an openness Kuznets curve? Evidence from Latin America

2008/9 Stephen Dobson, J ohn Goddard and Frank Stähler, Effort levels in contests: an empirical application of the Tullock model

2008/8 Juan Carlos Cuestas and Estefania Mourelle, Nonlinearities in real exchange rate determination: Do African exchange rates follow a random walk?

2008/7 Stephen Dobson and J ohn Goddard, Strategic behaviour and risk taking in football

2008/6 J oao Ricardo Faria, Juan Carlos Cuestas and Estefania Mourelle, Entrepreneurship and unemployment: A nonlinear bidirectional causality?

2008/5 Dan Wheatley, Irene Hardill and Bruce Philp, "Managing" reductions in working hours: A study of work-time and leisure preferences in the UK industry

2008/4 Adrian Kay and Robert Ackrill, Institutional change in the international governance of agriculture: a revised account

2008/3 Juan Carlos Cuestas and Paulo José Regis, Testing for PPP in Australia: Evidence from unit root test against nonlinear trend stationarity alternatives

2008/2 João Ricardo Faria, Juan Carlos Cuestas and Luis Gil-Alana, Unemployment and entrepreneurship: A Cyclical Relation

2008/1 Zhongmin Wu, Mark Baimbridge and Yu Zhu, Multiple Job Holding in the United Kingdom: Evidence from the British Household Panel Survey

\section{DISCUSSI ON PAPERS I N POLITI CAL ECONOMY}

2006/3 I oana Negru, On Homogeneity and Pluralism within Economics Schools of Thought

2006/2 David Harvie and Bruce Philp, Learning and Assessment in a Reading Group Format or Reading Capital... For Marks

2006/1 David Harvie, Bruce Philp and Gary Slater, Regional Well-Being and 'Social Productivity' in Great Britain'

2004/2 Massimo De Angelis and David Harvie, Globalisation? No Question: Foreign Direct Investment and Labour Commanded

2004/1 David Harvie, Value-Production and Struggle in the Classroom, or, Educators Within, Against and Beyond Capital

\section{DISCUSSION PAPERS I N APPLI ED ECONOMI CS AND POLI CY}

2007/2 Juan Carlos Cuestas, Purchasing Power Parity in Central and Eastern European Countries: An Analysis of Unit Roots and Non-linearities 
2007/1 Juan Carlos Cuestas and Javier Ordóñez, Testing for Price Convergence among Mercosur Countries

2006/2 Rahmi Cetin and Robert Ackrill, Foreign Investment and the Export of Foreign and Local Firms: An Analysis of Turkish Manufacturing

2006/1 Robert Ackrill and Adrian Kay, The EU Financial Perspective 2007-2013 and the Forces that Shaped the Final Agreement

2004/5 Michael A. Smith, David Paton and Leighton Vaughan-Williams, Costs, Biases and Betting markets: New evidence

2004/4 Chris Forde and Gary Slater, Agency Working in Britain: Character, Consequences and Regulation

2004/3 Barry Harrison and David Paton, Do 'Fat Tails' Matter in GARCH Estimation? Stock market efficiency in Romania and the Czech Republic

2004/2 Dean Garratt and Rebecca Taylor, Issue-based Teaching in Economics

2004/1 Michael McCann, Motives for Acquisitions in the UK

2003/6 Chris Forde and Gary Slater, The Nature and Experience of Agency Working in Britain

2003/5 Eugen Mihaita, Generating Hypothetical Rates of Return for the Romanian Fully Funded Pension Funds

2003/4 Eugen Mihaita, The Romanian Pension Reform

2003/3 Joshy Easaw and Dean Garratt, Impact of the UK General Election on Total Government Expenditure Cycles: Theory and Evidence

2003/2 Dean Garratt, Rates of Return to Owner-Occupation in the UK Housing Market

2003/1 Barry Harrison and David Paton, The Evolution of Stock Market Efficiency in a Transition Economy: Evidence from Romania 